NBER WORKING PAPER SERIES

\title{
DO HUMAN CAPITAL DECISIONS RESPOND TO THE RETURNS TO EDUCATION? EVIDENCE FROM DACA
}

\author{
Elira Kuka \\ Na'ama Shenhav \\ Kevin Shih \\ Working Paper 24315 \\ http://www.nber.org/papers/w24315 \\ NATIONAL BUREAU OF ECONOMIC RESEARCH \\ 1050 Massachusetts Avenue \\ Cambridge, MA 02138 \\ February 2018
}

We would like to thank Anna Aizer, Catalina Amuedo-Dorantes, Elizabeth Cascio, Aimee Chin, Chloe East, Hilary Hoynes, Chris Karbownik, Melissa Kearney, Ethan Lewis, Dan Millimet, Matt Notowidigdo, Francesc Ortega, Marianne Page, Bruce Sacerdote, Diane Schanzenbach, and Doug Staiger, as well as seminar participants at Northwestern MPES, University of Connecticut, Oklahoma State University, the US Census Bureau, and conference participants at the Barcelona GSE Summer Forum Migration meeting, UC Davis Alumni Conference, WEAI Conference, SEA Conference, SOLE Annual Meeting, and AEA Annual Meeting for helpful suggestions and feedback. We are also grateful to Marcella Alsan for her feedback and for generously sharing data on Secure Communities activation dates with us. The views expressed herein are those of the authors and do not necessarily reflect the views of the National Bureau of Economic Research.

NBER working papers are circulated for discussion and comment purposes. They have not been peerreviewed or been subject to the review by the NBER Board of Directors that accompanies official NBER publications.

(C) 2018 by Elira Kuka, Na'ama Shenhav, and Kevin Shih. All rights reserved. Short sections of text, not to exceed two paragraphs, may be quoted without explicit permission provided that full credit, including $\odot$ notice, is given to the source. 
Do Human Capital Decisions Respond to the Returns to Education? Evidence from DACA Elira Kuka, Na'ama Shenhav, and Kevin Shih

NBER Working Paper No. 24315

February 2018, Revised April 2019

JEL No. I20,I26,J1,J13

\section{ABSTRACT}

This paper studies human capital responses to the availability of the Deferred Action for Childhood Arrivals (DACA) program, which provides temporary work authorization and deferral from deportation for undocumented, high-school-educated youth. We use a sample of young adults that migrated to the U.S. as children to implement a difference-in-differences design that compares non-citizen immigrants ("eligible") to citizen immigrants ("ineligible") over time. We find that DACA significantly increased high school attendance and high school graduation rates, reducing the citizen-noncitizen gap in graduation by $40 \%$. We also find positive, though imprecise, impacts on college attendance.

Elira Kuka

Department of Economics

Southern Methodist University

3300 Dyer Street, Umphrey Lee Center

Dallas, TX 75275

and NBER

ekuka@smu.edu

Na'ama Shenhav

Department of Economics

Dartmouth College

6106 Rockefeller Hall

Hanover, NH 03755

naama.shenhav@dartmouth.edu
Kevin Shih

Department of Economics, CUNY Queens College kevinyangshih@gmail.com 


\section{Introduction}

The canonical model of human capital predicts that individuals respond to returns to education, as with any investment (Becker, 1964). However, even as the earnings gap between college- and non-college educated workers widens, the high school and college completion rate of many communities remains low (Bailey and Dynarski, 2011; Murnane, 2013). Undocumented youth, who account for $1.5 \%$ of the population of US minors, stand out in particular in this regard, with between $15 \%$ and $40 \%$ of young adults not having completed high school. ${ }^{1}$ Survey responses of this population suggest that the absence of legal status may inhibit investments in education (Wong et al., 2016), but also at play may be liquidity constraints, a high opportunity cost of schooling, or misperceptions of the returns to education. In this paper, we examine how the availability and design of legalization policies impact youth investments in human capital.

We take advantage of an ongoing policy "experiment" in the US, the institution of the Deferred Action for Childhood Arrivals program (DACA), which granted temporary legal status for undocumented youth. Enacted in August 2012, DACA extended temporary relief from deportation and work authorization - two years, initially, subject to renewal - to undocumented youth who were in school or had completed high school, and met other criteria based on age and year of arrival. DACA thus generates a discrete increase in the benefits associated with completing high school, and could also affect incentives for higher education. We discuss the range of direct and indirect benefits of participation in detail in Section 2. Despite this, previous studies of DACA's impact on schooling have ignored its effect on high school attainment.

Undocumented youth are a population of interest for several reasons. First, given the large migrant and refugee populations in the US and in Europe, and the intense policy debates on immigration reform, fully understanding the effects of DACA can assist in evaluating the benefits and costs of future immigration policies. Second, the fact that undocumented children have persistently low rates of high school graduation is worthy of attention in itself, as high school dropouts fare worse along multiple measures of health, family life, and economic success. Since this likely reflects, in part, uncertainty over employment and lower wage returns to education, policies that target these returns could improve a constellation of behaviors (Borjas, 2017). Finally, similar to other under-resourced populations, they face several disincentives to acquire human capital, such as lack of information about college applications, uncertainty over the costs and returns to schooling, and reduced access to credit

\footnotetext{
${ }^{1}$ Estimates of completed education vary by due to different methods of identifying undocumented youth. A range of estimates is provided in Erisman and Looney (2007) and Passel (2003).
} 
markets (Amuedo-Dorantes and Bansak, 2006; Osili and Paulson, 2009). Understanding the role of expected benefits of schooling for this population may inform the education choices of other low-income youth.

We navigate several empirical challenges to identify the causal response to DACA. First, there are no available data over this period that contain information on legal status and education for a large sample of youth. As a result, we follow the literature and in our preferred specification rely on the absence of US citizenship combined with Hispanic ethnicity as a second-best measure of undocumented status (Kaushal, 2006; Pope, 2016; Amuedo-Dorantes and Antman, 2016). Second, while non-eligible undocumented youth might ex-ante be a sensible comparison group, we show that the early age of arrival (before 16) and year of arrival (before 2007) requirements make eligible youth significantly more predisposed to stay in school relative to non-eligible undocumented youth. Instead, we use foreign-born citizens with identical age and year of arrival profiles as our comparison group. Third, we limit our attention to individuals who arrived by age 10 to address mechanical changes in sample composition that are tied to the year of arrival criteria for eligibility.

Hence, our difference-in-difference framework primarily compares Hispanic immigrant non-citizen child arrivals (treated) to immigrant citizen child arrivals (comparison) over time using the 2005 to 2015 American Community Surveys (ACS). This empirical design is similar in spirit to other recent policy evaluations that identify treatment effects by utilizing counterfactuals that vary along demographic traits, such as income, nationality, age, and/or year of arrival (Jackson, Johnson and Persico, 2016; Kleven et al., 2013; Marie and Zölitz, 2017). The data provide strong support for the identifying assumptions. We show that the average school attendance and high school completion of the treated and comparison groups tracked each other closely for seven years prior to DACA, and that there is an apparent closing of the gap in these outcomes after 2012. We then demonstrate that a large set of observable characteristics do not predict a differential improvement in schooling of the eligible population after DACA. As a result, our findings are largely insensitive to using alternative comparison groups or specifications, including propensity score methods.

We find that DACA had a significant impact on adolescents' educational investments. Our preferred estimates for Hispanics show that DACA led to a 2.2 percentage point (p.p.) increase in the school attendance of 14 to 18 year olds, a 2.5 percent increase, which narrowed the gap in attendance between citizens and non-citizens in this age range in our sample by $55 \%$. This rise in school attendance arguably includes many students who were on the margin of high school completion. We find that DACA increased high school completion of 19 to 22 year olds by 5.9 p.p., a 7.5 percent increase. Our results imply that more than 49,000 additional Hispanic youth obtained a high school diploma because of DACA, and that the 
gap in high school graduation between citizen and non-citizen youth in our sample closed by $40 \%$. Effects are smaller, though still positive, for individuals further from the typical high school enrollment age.

We find less precise evidence of impacts on post-secondary schooling, which was not required for DACA. Estimates from our main specification show that attainment of some college for 19 to 22 year old Hispanics increased by 1.3 p.p., but this effect is imprecisely estimated, and varies across alternative specifications. We interpret these results as suggestive, but not definitive, evidence of increases in college-going.

As a secondary identification strategy we use administrative data from California and leverage variation in the geographic concentration of eligible youth across counties. We analyze the impact of DACA on Hispanic high school enrollment and performance on the California High School Exit Exam (CAHSEE), a mandatory test required for graduation. We find a 4 p.p. increase in high school enrollment and a 2 p.p. increase in the number of CAHSEE test-takers, which corroborates well the ACS results on attendance. We also find increases in the pass rate among $12^{\text {th }}$ grade Hispanic students approaching their final opportunity to graduate, which indicates that DACA also induced greater schooling effort.

How large is the effect of DACA? Unpacking our results, we find that DACA had twice the impact on high school graduation of men (7.7 p.p.) as for women (3.5 p.p.). To interpret these magnitudes, we scale these impacts by the expected lifetime benefits of DACA, which we calculate with a simple model of lifetime expected earnings. This combines estimates of the reduction in the sex-specific average risk of deportation, skill-specific earnings in the US and abroad, and the difference between legal and non-legal earnings in the US. We obtain elasticities of high school around 0.05 for both men and women, which implies that the differential DACA response by gender was proportional to the expected benefits of the program. Further, we calculate that the semi-elasticity of high school graduation is 0.25, which is roughly $60 \%$ of semi-elasticity in Abramitzky and Lavy (2014), who study an increase in the return to schooling in Israeli kibbutzes. This suggests that DACA-eligible youth may be less sensitive to future returns, although these results could also be rationalized by misperceptions of the returns from DACA.

Our findings speak to central questions in education and immigration policy. First, we provide compelling evidence that a large share of the gap in the high school graduation of non-citizen youth and their citizen peers is attributable to the uncertain and limited returns to schooling. Previous papers show that reductions in the labor market incentives to stay in school, commonly induced through improvements in the low-skilled labor market, increase the likelihood of dropping out of high school and reduce college enrollment (Black, McKinnish and Sanders, 2005; Cascio and Narayan, 2017; Charles, Hurst and Notowidigdo, 2018; 
Atkin, 2016; Shah and Steinberg, 2017). However, responses to increases in future wage returns would not necessarily mirror these effects, since obtaining a degree, unlike dropping out, requires individuals to put forth effort, patience, and be sufficiently forward-looking (Oreopoulos and Salvanes, 2011). Prior work finds evidence for this behavior by exploiting novel, though often context- or skill-specific interventions, such as foreign firm entry, communal income-sharing, or experimental information treatments (Oster and Steinberg, 2013; Abramitzky and Lavy, 2014; Jensen, 2010; Wiswall and Zafar, 2014). ${ }^{2}$ We move these findings to a more general, national policy setting, and produce direct policy implications for raising the human capital of a large population of youth.

We also provide novel evidence of the response to a conditional and potentially temporary amnesty, whereas the majority of the literature focuses on unconditional amnesties. Among this literature, Cortes (2013) is the only study, that we are aware of, that examines the effects of an unconditional amnesty (IRCA) on education, ${ }^{3}$ and finds that college attendance substantially increases with amnesty. However, since that study does not account for changes in the sample age or age of immigration, the conclusions of that study are difficult to interpret.

We also contribute to a growing literature on the impacts of DACA, which finds that DACA improves health among children and adults (Hainmueller et al., 2017; Giuntella and Lonsky, 2018), reduces teenage pregnancy (Kuka, Shenhav and Shih, 2019), and improves adult labor market outcomes (Pope, 2016; Amuedo-Dorantes and Antman, 2017). Closer to this paper, Pope (2016), Amuedo-Dorantes and Antman (2017), and Hsin and Ortega (2017) analyze impacts on school attendance, focusing on older populations that have already completed high school, and therefore are already eligible for the program. We build on this prior work in several respects.

First, we study impacts on high school graduation, asking whether youth at an earlier stage of schooling are more responsive to DACA, perhaps because they want to become eligible. We provide a careful and transparent analysis of school attendance and high school completion, which yields new insights about the comparability of schooling outcomes between citizens and non-citizens in this population. Second, in our analysis of higher education

\footnotetext{
${ }^{2}$ Changing the cost of college, and hence the returns, through financial aid has also been found to increase post-secondary attainment; but there has been little evidence that aid enters into longer-term planning, such as by affecting the high school graduation decision (Deming and Dynarski, 2009).

${ }^{3}$ The Immigration Reform and Control Act of 1986 (IRCA) provided legal status to undocumented immigrants that entered the US before 1982 and met other criteria. In a similar vein, Liscow and Woolston (2016) and Felfe, Rainer and Saurer (2016) analyze the impact of citizenship on childhood and teenage schooling. However, the effect of citizenship may be quite different than a temporary or permanent amnesty, and the mixed-citizen families in Liscow and Woolston (2016) are not necessarily representative of all undocumented youth.
} 
we do not control for high school graduation, contrary to all prior studies of DACA on schooling. Consistent with selection bias, we show in sensitivity analyses that controlling for this covariate meaningfully reduces the estimate on school attendance for this sample. ${ }^{4}$ Third, we provide a two-pronged approach to analyzing schooling impacts, utilizing both individual-level survey data and county-level administrative records from California. The similarity of our estimates across these disparate sources helps reinforce our conclusions. These new findings inform the current debate on immigration policy, which has until now ignored the role for a path to legalization in producing an educated immigrant workforce.

The paper continues as follows. We provide further detail regarding the institutional details of DACA in Section 2. In Section 3 we examine the incentives of DACA and generate empirical predictions for schooling decisions. We discuss our data and empirical strategies in Sections 4 and 5. Section 6 presents results on schooling attendance, high school graduation and college. Section 7 provides evidence on exit exam performance. We discuss mechanisms and calculate implied schooling elasticities in Section 8, and conclude in Section 9.

\section{Institutional Background and Take-up of DACA}

Prior to DACA, there were multiple attempts to create a unifying federal policy for undocumented youth (Olivas, 2004). The DREAM Act, put forth in 2001, was the most prominent of these efforts, proposing a pathway to legalization for undocumented childhood immigrants conditional on meeting minimum education requirements. Momentum for the DREAM Act dissipated in 2010, however, after opposing political parties failed to come to a resolution. This legislative inaction led to the enactment of DACA by Executive Memorandum in June 2012, with the first applications being accepted in August 2012.

DACA provides two types of benefits to recipients. First, deportation is deferred, allowing beneficiaries to reside legally in the US. Since there are no available estimates of the deportation risk for undocumented youth, we try to approximate the size of this benefit using tabulations of removals for the population between age 18 and 39 by sex in 2012 from the Department of Homeland Security (Simanski and Sapp, 2012). On average, the annual deportation risk is $5 \%$, however, there is significant variation in the risk across sex, as men account for almost $90 \%$ of all deportations. This implies that the deportation risk is closer to $1.5 \%$ for women and $7.3 \%$ for men, taking differences in the size of the respective populations into account. ${ }^{5}$ It is worth noting that for both men and women, the perceived risk of

\footnotetext{
${ }^{4}$ For a more detailed discussion of this analysis as well as of these earlier works, see Appendix F.

${ }^{5}$ Tabulations on deportations from 2011 would be ideal, but only more aggregate statistics were available for that year. The overall annual deportation risk is calculated as 341,448 removals divided by Pew Center estimates population of 6.6 million (56\%) of 11.9 million undocumented immigrants (Passel and Cohn, 2009;
} 
deportation may be much higher than the actual risk, as recent surveys found that $59 \%$ of foreign-born Hispanics are somewhat or significantly concerned about the risk of deportation (Lopez et al., 2013).

Second, recipients may obtain an Employment Authorization Document (EAD), which grants recipients work authorization. An EAD also allows individuals to apply for a Social Security number, which opens the possibility of obtaining a state identification card or driver's license (in many states), and can reduce frictions in applying for a credit card, bank account, or loan.

Application requests are initially granted for two years, but recipients may request an extension through a renewal process. During our sample period, roughly $93 \%$ of recipients applied for renewal after the initial two-year period (Hipsman, Gómez-Aguiaga and Capps, 2016). The prevalence of renewals could reflect an expectation among recipients that the program would persist beyond two years (Nevarez, 2015). Efforts to expand the reach of DACA, though never passed, could have further added to expectations of the program's longevity. 6

DACA applicants must meet a suite of immigration, education, and criminal requirements, and pay a $\$ 465$ fee for approval. The first set of requirements are based on age and date of arrival in the US. We use these criteria to determine treatment status in our empirical analysis: (i) under 31 by June 15, 2012, (ii) entered the US before age 16, (iii) continuous residence in the US since June 15, 2007, and present at the time of application. Applicants must also be at least 15 years old, though we do not use this restriction in our analysis since young teenagers may age into eligibility. Second, applicants are not eligible if they have been convicted of a serious crime. Third, applicants must currently be in school, have graduated high school or obtained a general education development (GED) certificate. ${ }^{7}$ We do not use this last criterion to determine treatment as schooling is the potential outcome of the program that we focus on.

US Citizenship and Immigration Services (USCIS) began accepting applications for DACA on August 15, 2012, which was met by an immediate surge in applications. Figure 1(a) displays total initial applications and initial approvals by quarter from implementation through

Passel, 2005). Deportation rates by gender are calculated as the rate of 18 to 39 removals (81.4\%) times the share of male (female) deportations, $89.3 \%$ (10.7\%), times 419,384 alien removals - a total of 304,851 (36,527) deportations - divided by an estimated population of $4.1 \mathrm{M}(2.5 \mathrm{M}), 35 \%(21 \%)$ of 11.9 million unauthorized immigrants.

${ }^{6}$ President Obama announced an expanded DACA program in 2014 that would have extended eligibility to youth that arrived to the US by January 1, 2010; however, that version was never enacted.

${ }^{7}$ Applicants may substitute veteran status for this requirement, though in practice this seems to be rare, as a survey of DACA recipients revealed 100 percent had at least a high school diploma $(2.9 \%$ did not respond to the question) (Wong et al., 2016). 
2016. USCIS received nearly 150,000 applications in the fourth quarter of 2012, and 525,000 applications within 1 year - roughly $30 \%$ of the estimated eligible population of 1.7 million (Passel and Lopez, 2012). The rate of applications slowed beginning in 2013; USCIS received a total of 901,000 applications by the end of 2016. On September 5, 2017, President Trump ordered an end to DACA, leading to an immediate halt in the acceptance of new applications and renewals. However, ongoing court challenges have resulted in a continuation of renewals.

The geographic distribution of DACA applications reflects the concentration of undocumented populations in a handful of states. Figure 1(b) displays cumulative initial DACA applications through 2016 by state. California and Texas account for over 237,000 and 138,000 DACA applications, respectively. Illinois, New York, and Florida each account for roughly 40,000. These five states alone constitute $52 \%$ of the total number of applications. Moreover, the majority of applicants are from Latin America, with 600,000 applications from Mexico alone, with El Salvador, Guatemala and Honduras as the next highest applicant countries. Outside of Latin America, the largest sources of applicants are from Asia (South Korea and the Philippines) and the Caribbean (Jamaica and the Dominican Republic), although each of these countries contributed less than 5,000 total applications. ${ }^{8}$

\section{DACA Incentives for Education}

To motivate our empirical analysis, we use a simple human capital investment framework to examine how DACA might impact school attendance, high school completion, and college attendance of undocumented youth. For brevity, we present the basic intuition here and include further details in Appendix Section C.

We consider the schooling decision of an undocumented young adult in his final year of high school prior to DACA. If he leaves school, he will work full time and obtain an annual wage corresponding to his current legal status and schooling level. Given that he is undocumented, he will earn a lower wage relative to a worker with legal status that has the same skill level because of an unauthorized "wage penalty." ${ }^{9}$ If he remains in school, he foregoes current earnings, but will earn a higher wage with every year of additional schooling completed. Since undocumented youth are in the US illegally, he may be deported to his country of origin at any time. If he is deported, he may either work in his country of origin

\footnotetext{
${ }^{8}$ Qualitative evidence suggests that DACA application rates among Asians were low due to significant stigma associated with undocumented status, distrust towards authorities and the uncertain nature of the program, and lack of information about DACA through ethnic media (Singer, Svajlenka and Wilson, 2015).

${ }^{9}$ Works on this topic, including Rivera-Batiz (1999); Kossoudji and Cobb-Clark (2002); Borjas (2017), find that legalization raises wages between 6 to 14 percent.
} 
or attempt a return to the US. ${ }^{10}$ We assume that the probability of successful return is low for simplicity. ${ }^{11}$

Given these options, he chooses the level of education - dropout, high school graduate, or some college - that maximizes his lifetime expected earnings. For each level of education, lifetime earnings are given by the discounted sum of the US wages earned over the expected years in the US after completing his schooling and the discounted earnings in his country of origin earned over the remainder of his working years. His optimal education choice will therefore depend on the wage for each schooling level in the US and in his country of origin, and how many years he expects to remain in the US. It is worth highlighting that the expected duration in the US depends on his estimation of unobserved risks of deportation and successful re-entry, which may be imperfect. For example, survey evidence in Section 2 showed that youth may overestimate deportation risk. This would lead to biased perceptions of the expected years in each country, and cause education choices at baseline to differ from decisions taken under correct information.

By granting work authorization and reducing the risk of deportation, DACA raises the expected wage earned in the US - from the non-legal to the legal wage - and increases the expected number of years in the US. Since eligibility depends on having a high school diploma, this generates a discrete jump in the earnings function when one attains a high school degree. The size of this jump increases proportionally to the reduction in the deportation risk net of the probability of successful return - which extends the number of years one expects to spend in the US - and to the wage gain from remaining in the US, without legal status, instead of returning to one's country of origin. ${ }^{12}$ It also increases with the unauthorized wage penalty among high-school-educated workers, since this determines the size of the increase in wages when one obtains legal work authorization through DACA. Assuming that the opportunity cost of high school (i.e. the drop-out wage) and the probability of return is unchanged, this generates a clear prediction that high school completion will increase.

In addition, DACA increases expected college earnings, but since the opportunity cost of college also rises, as discussed above, the effect on the return to college and college attendance is ambiguous. All else equal, the lifetime return to a college education will increase after DACA if the unauthorized wage penalty for college-educated workers is larger than for high-

\footnotetext{
${ }^{10}$ Similar models that examine human capital decisions under uncertainty include Altonji (1993), Altonji, Blom and Meghir (2012) and Jayachandran and Lleras-Muney (2009).

${ }^{11}$ Bazzi et al. (2018) provide a nice summary on the risk of apprehension, with estimates of the probability of apprehension conditional on attempted return ranging from 40 to $60 \%$. We assume that the unconditional probability is likely to be much smaller, since not all migrants will attempt return.

${ }^{12}$ Since youth also now have short-term certainty over deportation risk, this also reduces the possibility of "mistakes" based on short-term misestimation of the deportation risk, which could increase individual and social welfare (see, e.g. Finkelstein and Notowidigdo (2018) and Bernheim and Taubinsky (2018)).
} 
school-educated workers, which has been documented in cross-sectional data (Borjas, 2017; Rivera-Batiz, 1999). It could also increase if the return to college in the US is higher than in the country of origin, since DACA ensures that more years will be spent in the US reaping those returns. Empirically, returns to college are roughly $50 \%$ higher on average in typical countries of origin for DACA youth (e.g. Mexico); ${ }^{13}$ however, the returns to experience for college-educated workers are twice as high in the US (Lagakos et al., 2018). Thus, over the life cycle, college-educated workers may still reap higher returns in the US. If these conditions are satisfied, DACA should encourage college attendance.

While we have thus far focused on the benefits of DACA that arise through expected wages, we acknowledge there are likely significant non-pecuniary benefits of DACA. For example, undocumented youth may have an incentive to finish high school just to avoid deportation if they have a preference for remaining in the US. (Vargas, 2012).

\section{Data}

We use data from the IPUMS ACS (Ruggles et al., 2017) for the period 2005 through 2015 to examine the education decisions of eligible and ineligible individuals. We use year of immigration and citizenship status, together with current age, to determine eligibility for DACA. ${ }^{14}$ Since age of arrival and year of birth are not reported in the survey, we assign age of arrival as the difference between year of arrival and the survey year minus current age.

Our main analysis focuses on a sample of immigrant youth ages 14 to 22 that arrived to the US by age 10 and by 2007. We focus on individuals born outside of the fifty US states to avoid the strong cultural, institutional, and structural divisions between natives and immigrants (LaLonde and Topel, 1992; Borjas, 1985, 2017). We justify the age of immigration criteria in Section 5. We conduct our analyses on various subgroups of youth, reflecting the distinct ages at which different decisions are taken. We use a sample of teens between the ages of 14 to 18 to examine high school attendance, and a sample of young adults between the ages of 19 and 22 to examine post-secondary school attendance and high school completion.

Importantly, the ACS collects information on all households living in the US, irrespective of their citizenship or legal status. Pope (2016) details that the sampling procedure for the

\footnotetext{
${ }^{13}$ We calculate the ratio of the return to college in countries of origin and the return to college in the US by taking the ratio of column 5 and column 6 from Table 5 of Clemens, Montenegro and Pritchett (2016).

${ }^{14}$ Year of immigration comes from the response to the question, "When did this person come to live in the United States?" Redstone and Massey (2004) show that the ambiguity in the wording of this question leads to various interpretations in reporting, which may cause us to misassign treatment in some cases. We assume that this misinterpretation is not discontinuous after 2012.
} 
ACS draws from the universe of addresses, and is therefore likely to be representative of the unauthorized immigrant population. Moreover, the Census Bureau also takes several steps to encourage responses to the ACS (Liscow and Woolston, 2016). The Census is not permitted to share personal information with other government agencies, and communicates this confidentiality policy in the survey. Particularly relevant for our context, the Census also performs outreach to Hispanic organizations, and makes the survey available in Spanish.

As a secondary source of schooling outcomes, we turn to administrative data from California. California has the largest undocumented population among all states and accounts for nearly 30\% of DACA-recipients. We obtain county-level administrative data on Hispanic high school enrollment from the California Department of Education (CA DOE), and county-level Hispanic performance on the California High School Exit Examination (CAHSEE), including average test scores, the number of test takers, and the number of students passing the exam by test subject. CAHSEE data is available starting in academic year 20056, hereafter 2005, when the CAHSEE was launched, through 2014, after which the CAHSEE was suspended. Enrollment data are available for the entire period, from 2005 to 2015.

We provide further detail on the sample construction and variable definitions in both these data sources in the Data Appendix.

\section{$5 \quad$ Empirical Strategy using Individual Eligibility}

Our empirical strategy identifies DACA-ineligible immigrant youth whose education decisions follow similar patterns to eligible youth prior to DACA, and use a difference-indifferences strategy to measure the impacts of the policy. We use the estimating equation,

$$
Y_{\text {igast }}=\alpha_{0}+\alpha_{1} \text { Eligible }_{g}+\alpha_{2}\left(\text { Eligible }_{g} * \text { Post }_{t}\right)+\beta X_{i g}+\gamma_{s t}+\gamma_{r t}+\gamma_{a t}+\epsilon_{\text {igast }}
$$

where $Y_{\text {igast }}$ is the outcome for an individual $i$, who has eligibility status $g$ (eligible or not eligible), and is currently age $a$ and living in state $s$ in year $t$. Eligible $_{g}$ is a function of whether an individual is (i) not a citizen and (ii) meets DACA's age and year of arrival requirements. We impose the latter criteria by restricting our sample to immigrant youth who arrived by 2007 and by age 10. This also corrects for a mechanical shift in sample composition whereby moving forward in survey time reduces the maximum age of arrival of eligible youth, which could have an independent effect on our estimates (Bleakley and Chin, 2010). ${ }^{15}$ As a result, Eligible $g$ is simply an indicator for being a non-citizen. Post Pis $_{\text {an }}$

\footnotetext{
${ }^{15}$ Without this adjustment, the sample of eligible 18 year olds in 2011 would include those that arrived by age 14; but in 2015 would only include those that arrived by age 10 .
} 
indicator that equals 1 beginning in the year 2012 .

We account for fixed individual characteristics by including a vector of controls, $X_{i g}$, which include dummies for sex, year of immigration, birth region, ${ }^{16}$ as well as age of immigration-by-eligibility and age-by-eligibility fixed effects. We include state-by-year $\left(\gamma_{s t}\right)$ and race-by-year fixed effects $\left(\gamma_{r t}\right)$, to absorb state- and race-specific shocks, and age-by-year dummies $\left(\gamma_{a t}\right)$ to account for cohort effects. We use sampling weights in all regressions.

The interaction between Eligible and Post, captured by $\alpha_{2}$, provides the average effect of DACA after 2012. If individuals are unable to adjust education decisions immediately, this estimate will provide an attenuated estimate of the policy effect. Therefore, our preferred specification replaces Post $_{t}$ with indicators for each year to estimate dynamic treatment effects. This event study approach also allows us to visualize any difference between the eligible and ineligible groups before and after the policy went into effect as a test of the identification assumption.

We obtain standard errors for our estimates using two methods. First, we cluster our standard errors at the state level, as is commonly done for difference-in-differences with a federal policy (e.g. Hoynes, Miller and Simon, 2015), which we report in all tables. Second, we obtain p-values using permutation tests that compare our estimates of the effect of DACA to estimates of placebo policies, following Conley and Taber (2010) and Agarwal et al. (2015). Since our main analysis covers four "treated" years, we assign a placebo DACA policy to four randomly chosen years drawn without replacement, allowing the remaining seven years to serve as the pre-period. We then estimate the effect of the placebo DACA policy. We construct p-values by comparing our estimate to the distribution of estimates from 1,000 placebo DACA simulations.

\subsection{Intent-to-Treat (ITT) Interpretation}

Our measure of eligibility is measured with noise, as non-citizens include green card holders and temporary visa holders. This causes our estimated effects of DACA eligibility to be a "scaled-down" estimate of the true ITT effect due to the possible inclusion of individuals who are not undocumented. Drawing on a number of sources, which we synthesize in Appendix B, we calculate that $55 \%$ of all US non-citizens and $45 \%$ of non-citizens ages 18-24 are legal residents. As a result, our difference-in-difference estimates for the whole sample are likely to underestimate the true effect of DACA by $45 \%$.

To get closer to the true ITT effect, we separately analyze groups that have a higher share of undocumented individuals among those that we assign eligibility. We first analyze

\footnotetext{
${ }^{16}$ We assign countries of birth into 5 groups: Mexico, Central and South America, UK and Europe, Asia, and Rest of the world.
} 
treatment effects among Hispanics. Our best estimates suggest that Hispanics comprise $78 \%$ of undocumented immigrants and that $72 \%$ of all Hispanic non-citizens are undocumented, which, given our earlier estimates, is likely to be a lower bound on the share undocumented among non-citizen Hispanic youth.

Second, we analyze individuals from countries that have a DACA take-up rate above $30 \%$ ("high take-up"), which have a high share of undocumented due to overlap with the Hispanic subgroup, but may have greater familiarity with DACA. ${ }^{17}$ While there is substantial overlap between our Hispanic and high take-up samples, these two groups are not identical. Among foreign born Hispanics ages 14 to 22, $86 \%$ of respondents come from high take-up countries, and among individuals born in high take-up countries, $93 \%$ are Hispanic.

Our baseline estimates are also "local" in the sense that they omit any effect on undocumented teens who immigrated after age 10, who account for roughly $40 \%$ of 14 to 18 year old non-citizens in the ACS. We find slightly larger treatment effects when we include individuals who arrived between the ages of 11 and 16 (see Section 6.3).

\subsection{Baseline Sample Characteristics}

Appendix Table A.1 provides descriptive statistics of the Hispanic eligible and comparison groups at baseline, from 2005 to 2011. Roughly 24\% of the comparison group were born in US territories, primarily Puerto Rico, 19\% were born abroad to American parents, and 57\% gained citizenship through naturalization. Relative to the treatment group, high-school-aged youths in the comparison group are more likely to have health insurance coverage, English fluency, and parental college, and are less likely to be in poverty; but are also more likely to have a single mother and similarly-likely to have had a recent birth. As a sensitivity exercise, we use propensity score methods to generate balance in demographics across our treated and comparison groups (see Section 6.3.)

Note that while other non-eligible immigrants could in theory serve as a comparison group, namely non-citizens who do not meet the age and/or year of arrival criteria, Appendix Figure A.1 shows that the common trends assumption does not hold for these groups. This reinforces our intuition that the age and year of arrival of immigrants strongly influence school attendance and that the comparison group should match these characteristics of the eligible population.

\footnotetext{
${ }^{17}$ These countries are El Salvador, Mexico, Uruguay, Honduras, Bolivia, Brazil, Peru, Ecuador, Jamaica, Guatemala, Venezuela, Dominican Republic, and Colombia. Statistics are based on the Migration Policy Institute's (MPI) estimates of the DACA-eligible population and application rates by country, available at http://www.migrationpolicy.org/programs/data-hub/ deferred-action-childhood-arrivals-daca-profiles (accessed 8/16/2017).
} 


\subsection{Evidence on Identifying Assumptions}

Our identification relies on the assumption that in the absence of DACA, citizen child arrivals would have exhibited similar trends to non-citizen child arrivals. We examine the plausibility of this assumption in two ways. First, we ask whether the gap in predicted schooling, based on observable characteristics, was constant around the timing of DACA. To obtain predicted schooling outcomes, we generate fitted values for the entire sample period from a regression of schooling outcomes on a large number of demographic characteristics from 2005 to 2011. ${ }^{18}$ Appendix Figure A.2 presents event study estimates of Equation 1 for predicted school attendance and high school completion. In favor of our strategy, the coefficients are generally insignificant and show no upward trend in predicted schooling. Hence, any change in education outcomes of non-citizens relative to citizens post-DACA must come from a change in behavior, not compositional changes.

Second, we examine observed trends in schooling of our treatment and comparison groups. Panel (a) of Figure 2 shows that the school attendance trajectories of these two groups tracked each other closely from 2005 to 2011, with a constant gap of roughly 4 percentage points over this period. Strikingly, after 2012, the difference narrows by half, as attendance of the eligible group increases by over 2 percentage points. Panel (b) shows a similar, unexpected closure of the gap in high school completion in 2012. These patterns provide support for common trends as well as suggestive evidence of a DACA treatment effect on education decisions. Further, the few examples where the trends appear to deviate in the raw means seem to be explained by small changes in observable characteristics, which we control for in our regressions. ${ }^{19}$

We also require there to be no other simultaneous policies targeting undocumented youth. DACA was the only such national policy implemented during our sample period; we examine the role of local-level policies in Section 6.3.

\footnotetext{
${ }^{18}$ These include (i) indicators for age, race, sex, age and year of immigration, citizenship status, birthplace, language, state, and metropolitan status; and (ii) health insurance coverage, presence of mother and father in the household, parental college attendance, family size, number of siblings, household poverty status, and the presence of a food stamp recipient in the household. The results are similar, and more precise, if we only use the first set of variables, which are less likely to be outcomes of DACA.

${ }^{19}$ For example, the rise in non-citizen high school graduation between 2010-2011 is mirrored in our prediction of high school completion in Appendix Figure A.2.
} 


\section{ACS Results}

\subsection{School Attendance}

We first examine whether DACA led to increased school attendance. Figure 3 presents event studies for school attendance of adolescents ages 14 to 18. Estimates for the whole sample appear in Panel (a), while those for Hispanics and the high take-up sample appear in panels (b) and (c). The figures show that there was not a pre-existing trend between our eligible and comparison groups prior to 2012. After the enactment of DACA in 2012, eligible youth experience an immediate and persistent increase in school attendance.

The difference-in-difference results appear in Panel (a) of Table 1. In line with the event studies, we find that DACA led to statistically significant increases in school attendance of 14-18 year olds, with a 1.2, 2.2 and 2.9 p.p. increase among all immigrants, Hispanics and the high take-up sample, respectively, which is equivalent to a 1.3 to 3.3 percent increase. To give a sense of the magnitude of this effect, the point estimates for Hispanics are slightly higher than the within-sibling impact of citizenship status on school attendance (Liscow and Woolston, 2016). Panel (b) shows the effect of DACA among college-aged individuals, ages 19 to 22, with event study figures in Appendix Figure A.3. We find positive, statistically insignificant point estimates for this age category.

\subsection{High School Completion and College Attendance}

Next, we investigate whether increases in school-going resulted in a higher rate of high school completion, defined as having earned either a high school diploma or GED. ${ }^{20}$ We hypothesize that DACA will have the largest impact on youth that had not yet or just recently dropped out of school by DACA enactment (ages 19 to 22), but also examine impacts on 23 to 30 year olds, all of whom would have likely left high school before DACA.

The results, presented in first three columns of Table 2, show that DACA increased high school completion for all age categories. Panel (a) shows completion rates of 19 year olds increased by 4.6 p.p. overall, with larger effects for Hispanics and the high take-up sample, who experienced increases of 6.5 and 8.5 p.p., respectively. This represents a sizable increase, both in absolute terms and relative to other interventions, particularly given the low $75 \%$ completion among Hispanics.

Panel (b) of Table 2 shows the impact for 19 to 22 year olds is somewhat smaller, ranging from 3.8 to 6.4 p.p., though more precisely estimated due to the larger sample size. The

\footnotetext{
${ }^{20}$ We would like to be able to separately estimate the effect on diploma and GED, but the ACS only provides information on the type of high school degree for the subsample of individuals that completed exactly high school.
} 
effect for 23 to 30 year olds is quite a bit more muted. We find a marginally significant 1.5 p.p. effect among Hispanics, and a similarly sized, but statistically insignificant effect for the high take-up sample. This is perhaps not surprising since this group is likely to have work or family commitments that would pose a barrier to returning to school.

The event studies in Figure 4 allow us to examine the timing of the effects for the 19 to 22 sample. Mirroring the increase in school attendance, we see that the increase in high school completion began in the year following the DACA announcement, and that the gap in completion rates was steady prior to the policy. ${ }^{21}$ There is also a slight upward trend in the point estimates over time, although the point estimates are noisy, and we cannot reject a constant effect.

To put our findings into perspective, multiplying the 830,700 eligible Hispanics age 19-22 represented in the ACS by our estimated 5.9 p.p. increase in high school graduation implies that DACA led to over 49,000 additional high school graduates. As a result, the 15 p.p. gap in high school completion between Hispanic non-citizen youth and their citizen immigrant peers in our sample - which is roughly the same when we adjust for observable characteristics - narrowed by $40 \%$.

Finally, in the last three columns of Table 2 and Appendix Figure A.4 we analyze impacts on college-going, which we define as having attended any post-secondary schooling. In general, we find positive, but imprecise effects on the order of 1 to 3 p.p. for young adults ages 19 to 22 . Even so, we are still able to rule out declines in college attendance larger than 2.2 p.p. for Hispanics. This lower bound is more positive than the upper bound of effects in Amuedo-Dorantes and Antman (2017) and Hsin and Ortega (2017), and similar to the mean effect in Pope (2016). ${ }^{22}$ An exception to this is that we find a statistically significant 5.7 p.p. increase in college-going for 19-year-olds in the high take-up sample, a 17 percent effect. This could reflect true heterogeneity in the treatment effect on college, but may also have occurred in this subsample by chance.

A limitation of these results is that they do not allow for differential linear trends in college-going between citizens and non-citizens, which may be important in part due to recent changes in tuition policies for undocumented students (Mendoza and Shaikh, 2015). If we account for differential trends by eligibility, we find a significant 3 to 7 p.p. increase in

\footnotetext{
${ }^{21}$ We looked into the plausibility of an effect on high school graduation in 2012, following either DACA's announcement in June or enactment in August, by examining the incidence of obtaining a diploma between July and December. Using the National Longitudinal Study of Youth 1997 (NLSY97), we find that one quarter of students that complete high school in 5 years obtain a diploma between August and December (see Appendix D). Further, this could be a lower bound on the scope for completing in the first semester, if those who do not return to complete a degree are only deficient one semester of work.

${ }^{22}$ We provide an in-depth comparison of the estimates across these studies in Appendix Section F.
} 
college attendance (see Section 6.3 for details). ${ }^{23}$ Overall, we view this as suggestive, though not definitive, evidence of increases in college, particularly with respect to the prior trend in undocumented attendance. Importantly, the fact that we find a consistent pattern across specifications should positively update and perhaps widen the confidence interval of college impacts from earlier studies.

\subsection{Robustness}

These results indicate that DACA had a significant impact on youth schooling decisions. We now perform sensitivity exercises to test alternative explanations for these findings and specifications for the analysis.

First, we examine whether our conclusions change when we calculate p-values using the permutation tests described in Section 5. Figure 5 shows the histogram of placebo estimates for Hispanic school attendance for ages 14 to 18 (Panel (a)) and high school graduation for ages 19-22 (Panel (b)), along with a vertical line representing our difference-in-difference estimate. The permutation tests yield p-values less than 0.01 for both outcomes, which suggests that our clustered standard errors for high school completion may in fact be too conservative.

Second, we test the sensitivity of our main findings to alternative sample selection criteria and refinements. The first column of Table 3 reprints our baseline results for school attendance, high school completion, and college attendance. In the following columns, we re-estimate results using alternative age-of-arrival restrictions, keeping only those that arrived by age 6 (Column 2) or age 16 (Column 3). We then expand the comparison group by sequentially adding in non-citizens and citizens who arrived in the US after turning 16 (Column 4), individuals who arrived after 2007 (Column 5), and US-born individuals (Column 6 ). The magnitude of our estimate is sometimes attenuated across these columns, but the precision and pattern of effects are very similar. In the last column we recode our eligibility indicator to exclude non-citizens that live in households with veterans or report positive Social Security or welfare receipt (Liscow and Woolston, 2016). The estimated effects remain similar to our baseline effects.

Third, we account for potential differential linear pre-trends in the outcome by eligibility status in two different ways. Our less-preferred approach is to control for the interaction between eligibility and year in Equation 1. Instead, we favor a "two-step" approach in

\footnotetext{
${ }^{23}$ In results not reported, we test whether the impact on college is tied to the cost of tuition by allowing for differential effects in states where undocumented are eligible for in-state tuition. Intuitively, we find that the impacts on college are between 3 and 6 points higher in states with in-state tuition, but these differences are not statistically significant.
} 
which we (i) regress each outcome and covariate on the interaction between eligibility and year using pre-period data, and obtain residuals; and then (ii) estimate Equation 1 on the de-trended data, adjusting standard errors to account for the parameters in (i) (GoodmanBacon, 2016). We favor this approach because in the presence of dynamic treatment effects, directly controlling for linear trends can bias estimates (Wolfers, 2006; Lee and Solon, 2011; Borusyak and Jaravel, 2016) and for transparency. Appendix Table A.2 shows our qualitative results are unchanged when we perform these adjustments, though we find larger and more precise effects on college-going when using the "two-step" approach.

Fourth, we consider other policies affecting undocumented immigrants during this period. While DACA was the only national level policy, there were several local level programs that were active, most notably Secure Communities, 287(g) agreements, and the Criminal Alien Program. These policies focused on detainment or deportation of undocumented criminals, which could have altered schooling decisions. Among these program, Secure Communities stands out as a primary threat to identification as it experienced large expansions that coincided with DACA and influenced take-up of public assistance (e.g. Alsan and Yang, 2018). ${ }^{24}$ To address this potential confound, we control for the county-by-year rollout of Secure Communities using data from Alsan and Yang (2018), shown in Appendix Figure A.5. Our estimates are unaffected by this control.

Fifth, since our analysis relies on survey data, one could be concerned that DACA might lead to changes in participation in the ACS, which could bias our estimated effects. Recall, however, that Figure A.2 showed that we cannot predict our findings based on a large number of characteristics of survey participants. Hence, this explanation seems less plausible.

Finally, we also present propensity-score-re-weighted estimates as an additional method of controlling for omitted variable bias. This addresses potential concerns that the imbalance in background characteristics between eligible and non-eligible youth influences our results. We predict the likelihood of being eligible for each subsample and age group using a probit regression with a large number of individual and household covariates, described in the Appendix. We then re-estimate our regressions using inverse-propensity score weighting. Appendix Table A.3 shows that the effects are the same as when we do not use this reweighting.

\footnotetext{
${ }^{24}$ Since $287(\mathrm{~g})$ agreements took place before DACA (Watson, 2013), that policy is less likely to contaminate our effects, and we find no evidence of significant responses in our pre-trend analysis. Furthermore, Dee and Murphy (2018) find that 287(g) actually reduced high school enrollment, which implies that contamination from this program are likely to imply that our estimates are conservative. The Criminal Alien Program (CAP) also saw expansions many years prior to DACA. Recent changes dedicated additional funding to CAP circa 2014, after DACA was already implemented (Cantor, Noferi and Martinez, 2015). Nonetheless, we see treatment effects immediately after the implementation of DACA and before CAP funding in 2014.
} 


\section{Schooling Evidence from California}

Thus far, we have shown that DACA increased individual reports of high school attendance and completion. We use administrative data from California to extend these results in two ways. First, we examine whether DACA led to growth in high school attendance using official school reports, which addresses potential concerns about strategic reporting of school attendance. Second, we use data on the CAHSEE, a mandatory exam for graduation, to assess whether test performance changed alongside increases in attendance. The CAHSEE consists of two subject exams in mathematics and english language arts (ELA), and students must pass both in order to graduate. All students take the exam for the first time in $10^{\text {th }}$ grade, and those that do not pass may take the exam again in $11^{\text {th }}$ and $12^{\text {th }}$ grades.

\subsection{Empirical Strategy using Geographic Eligibility}

Since administrative schooling data from California are available at the county-level, we adapt our empirical strategy to exploit variation in the concentration of eligible youth across counties. ${ }^{25}$ In particular, we compare the outcomes of Hispanic youth in counties that have a high share of eligible Hispanics relative to counties with a low share of eligible Hispanics, before and after DACA. ${ }^{26}$

We use the estimating equation:

$$
Y_{c t}=\alpha+\beta \text { HiShareElig } \text { S }_{c} \text { Pst }_{t}+\gamma_{c}+\gamma_{t}+\theta U_{c t}+\epsilon_{c t}
$$

where $Y_{c t}$ is a school performance measure for county $c$ in year $t$ and HiShareElig $g_{c}$ is an indicator for having an above-median average share of eligible individuals among the Hispanic population ages 14 to 18 during the pre-DACA period between 2005 and 2011. We will refer to these as "high-undocumented" counties, and below-median-share counties as "low-undocumented" counties. We include county fixed effects, $\gamma_{c}$, to control for fixed differences in school quality and county composition; year fixed effects, $\gamma_{t}$, to control for statewide trends and changes in other state or federal policies; and county unemployment rates, $U_{c t}$, to account for differences in local economic conditions, especially during the

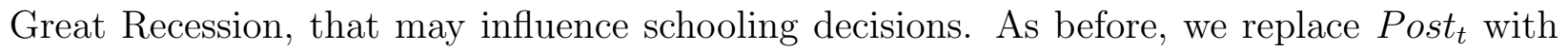
year indicators to estimate treatment effects over time. Standard errors are clustered at the

\footnotetext{
${ }^{25}$ This approach is similar to Cascio and Lewis (2018), who also utilize variation in the geographic concentration of unauthorized immigrants in the absence of individual-level information on legal status.

${ }^{26}$ Since we construct this treatment variable using the ACS, our analysis focuses on the 34 of California's 58 counties that are identified in the ACS, who account for over $88 \%$ of total K-12 enrollment during the 2005-2015 period.
} 
county level.

\subsection{California Schooling Results}

We first analyze impacts on high school enrollment. We complement our main results by examining two different measures of attendance, high school enrollment and the number of CAHSEE test-takers. To account for differences in population sizes across counties, we standardize all attendance measures by the average population of Hispanics ages 14-18 between 2005 and 2011. This serves two purposes: $(i)$ it allows us to validate our earlier results using administrative data and slightly different identifying assumptions, and ( $i i$ ) it allows us to establish a "first-stage" on schooling attendance in this data before examining test scores.

Figure 6 presents the event study estimates for high school enrollment in Panel (a) and the number of Math and ELA test takers in Panels (b) and (c), respectively. Prior to 2012, the gap between high-undocumented counties and low-undocumented counties was relatively constant. All three figures show a clear rise in attendance in high-undocumented counties after DACA. The difference-in-difference estimates for these outcomes, included in Table A.4 and in the notes below the figure, indicate that high-undocumented counties experienced a marginally significant 4.2 p.p. increase in high school enrollment and a significant 1.3 to 2.4 p.p. increase in ELA and Math CAHSEE test-takers, respectively. ${ }^{27}$ Despite the different data source and identification, these estimates also show positive impacts on school attendance. $^{28}$

Next, we analyze whether students put forth greater effort on exams. Appendix Table A.5 presents the effects on test performance for $10^{t h}, 11^{t h}$, and $12^{t h}$ graders. Among first-time test takers in the $10^{\text {th }}$ grade, DACA led to statistically significant decreases in performance on both the Math and ELA exams. This decline should be interpreted in light of the increases in attendance, and hence the number of test-takers. Marginal undocumented students those induced by DACA to stay in school - are likely to be less prepared on average for the exam and lower-scoring. Importantly, however, the magnitudes are quite small. The share of test takers passing each exam falls by 1 to 2 percentage points off of a baseline pass rate of $74 \%$ for both Math and ELA. At the same time test scores decline by 1.6-3 points from average scores of around 370 in Math and ELA.

Among repeat test-takers in $11^{\text {th }}$ and $12^{\text {th }}$ grades, we find mixed results. The effect on

\footnotetext{
${ }^{27}$ The p-value is 0.108 for high school enrollment; $p<0.01$ for Math test-takers, and $p<0.10$ for ELA test-takers.

${ }^{28}$ In Appendix B, we calculate that the scaling factor to convert these estimates to ITT is between 9.7 and 16.3, which implies an order of magnitude larger enrollment effect relative to our ACS estimates. We speculate that this may be an overestimate of the ITT if non-citizens are under-reported in high-undocumented counties, although large effects are plausible if native Hispanics experienced spillover effects from the policy.
} 
$11^{\text {th }}$ grade performance is statistically insignificant, but average performance appears to rise for $12^{\text {th }}$ grade students. Pass rates for the ELA exam increase by a statistically significant 1.7 percentage points, which translates to a modest $7 \%$ of the mean. This suggests that undocumented students facing their final attempt to graduate and qualify for DACA may have increased effort, particularly with respect to English language.

\section{Discussion}

Having focused on the average reduced-form effects on different education choices, we now separately consider the importance of deferral from deportation as an incentive for schooling. We then use our difference-in-difference estimates to construct a range of elasticities of schooling to changes in returns based on lifetime earnings, and compare these to similar estimates in the literature.

\subsection{The Role of Deportation Risk}

We begin by analyzing differential schooling responses across men and women, recalling that the national deportation risk for men is over 4 times higher than the risk for women. Table 4, which focuses on 19-22 year olds, shows that the effects for high school completion are more than twice as large for young men as for young women, and that these differences across genders are statistically significant at the $10 \%$ level. We find no significant difference between men and women in college attendance. These results are consistent with youth responding to the differential national patterns in deportation risk across gender. Further, in the Appendix, we rule out differences in opportunity costs as an alternative explanation. ${ }^{29}$

As a second test of the role of deportation risk, we ask whether schooling responses are correlated with local deportation risk, which we measure using the deportation rate in one's state of residence. We take a non-parametric approach, estimating difference-indifference coefficients by state, and then plotting the coefficients, ranked in ascending order of state's deportation rate (see Appendix E for data details). Figure E.2 shows no systematic relationship between the state deportation risk and the DACA-induced increase in schooling. For instance, we find similar-sized effects on teenage schooling in Arizona and New Jersey despite the fact that we estimate the deportation risk to be over 12 times higher in Arizona. ${ }^{30}$

\footnotetext{
${ }^{29}$ In particular, Appendix Table A.6 shows that men substituted towards schooling from work and idleness, while women entirely substituted from idleness, perhaps due to a lower incidence of teenage births (Kuka, Shenhav and Shih, 2019).

${ }^{30}$ Further, in results not reported, we find that states with a higher deportation risk do not have a lower "legal premium," which could offset the response to deportation risk.
} 
We come to the same conclusion when we allow the effect of DACA to vary linearly with the state-level deportation risk.

One interpretation of these results is that youth do not value reductions in deportation risk. Considering the magnitude of the schooling response, this seems unlikely. Our calculations of the increase in lifetime earnings resulting from DACA, which we discuss in more detail below, reveal that the expected earnings benefits from lower deportation risk account for $37-50 \%$ of the total benefits of DACA. Therefore, removing this benefit would imply doubling the schooling responses for each dollar of earnings benefits. We cannot rule out this possibility, but it seems less plausible. Our preferred interpretation is that youth react to perceived deportation risk, which is likely to be different than actual measured risk. For example, youth in low-deportation rate states may overestimate the likelihood of deportation, consistent with the survey evidence in Section 2, or youth in high deportation states may overestimate the probability of return to the US conditional on deportation. These misperceptions could rationalize the similar schooling responses across states.

\subsection{From Reduced Form Effects to Schooling Elasticities}

We now convert our difference-in-differences estimates to the intent to treat (ITT) effects of DACA, and use these estimates to obtain a range of elasticities of schooling to lifetime earnings.

First, to recover the ITT effect of DACA we rescale our treatment effects to account for the fact that the eligible group includes legal immigrants. Given that our best estimates indicate that roughly $72 \%$ of non-citizen Hispanics are undocumented, we rescale our treatment effects by a factor of 1.39 to recover the ITT effects. Since the share undocumented tends to be higher for youth, we take this as a lower bound of the share of non-citizen youths that are undocumented, and hence our ITT effects are an upper bound. ${ }^{31}$

Second, we calculate the percent change in expected returns to schooling from DACA by taking the difference in expected lifetime earnings before and after DACA. This can be written as a function of: (1) the expected years working in the US and Mexico pre and post-DACA; and (2) home country, undocumented US, and documented US wages for each education level (see Appendix $\mathrm{C}$ for more detail). We do not attempt to monetize the nonpecuniary benefits of DACA, such that our wage estimates are thus a lower bound of the total benefits of DACA, which makes the estimated elasticity an upper bound on the sensitivity of schooling to total schooling returns.

\footnotetext{
${ }^{31}$ In contrast, since only $55 \%$ of eligible teens in the whole sample are likely to be unauthorized, the ITT effect is roughly $80 \%$ larger than the difference-in-difference estimates for the whole sample.
} 
We draw on a variety of sources to estimate these inputs, summarized in detail in Appendix Table C.1. To calculate the expected duration of years working in the US, we subtract the cumulative probability of deportation from the total number of working years. In our preferred estimate, we calculate this deportation risk for each age and sex prior to DACA using the number of removals from the US in 2012 (Simanski and Sapp, 2012) divided by the estimated population of undocumented immigrants. We conservatively assume for most calculations that the probability of deportation only declines to 0.5 p.p. during DACA receipt, and for simplicity assume that the perceived probability of return is zero.

We also consider three time horizons over which eligible individuals may have expected DACA benefits to last; 4 years, 6 years, or permanent. Although there is no data on these expectations, we surmise that 4 years may be the minimum expectation, given that the Obama administration was re-elected for a 4 year term soon after the passage of DACA.

We assign the US wages for each legal status (citizens, non-citizens) and education level as the average wages of foreign-born adults that meet the sample immigration requirements in the 2009-2011 ACS. Since the vast majority of the DACA-eligible population was born in Mexico, we proxy the wage in the country of origin as the average wage in Mexico by education and sex calculated from the IPUMS 2010 Mexico Census (Minnesota Population Center, 2018).

Column (1) of Table 5 shows the elasticity of high school completion under each of these scenarios using the rescaled (ITT) schooling estimates for Hispanics. Intuitively, the elasticity is larger when we assume shorter expected durations of DACA, since the benefits of DACA accrue over a shorter period. Our preferred elasticities rely on six years of duration, the actual duration of DACA. Under these assumptions, the elasticity of high school completion is between 0.05 and 0.08 . Men and women exhibit similar responsiveness, indicating that the varying magnitudes of the difference-in-differences estimates are proportional to the respective changes in high-school-educated earnings. ${ }^{32}$

The remaining two columns show the sensitivity of our elasticity calculations to misperceptions in the deportation risk. In column (2) we assume the perceived risk to always be 0 , and hence that the only earnings benefit from DACA comes from the higher wages afforded by legal status. Since the increase in the return to high school is much lower under this assumption, our average elasticity estimate doubles to 0.109. In column (3) we assume a $30 \%$ deportation rate, the highest from our state deportation rate calculations. These elasticities are similar to the baseline estimates. ${ }^{33}$

\footnotetext{
${ }^{32}$ See Appendix Table C.2 for the equivalent college enrollment elasticities.

${ }^{33}$ The elasticity for $30 \%$ deportation risk is typically lower than for the age-varying deportation risk, consistent with higher benefits. Occasionally the $30 \%$ elasticity is higher, reflecting a higher return to high school at baseline (which reduces the percent increase in the return).
} 
Is the size of our DACA responses comparable to prior work? The most similar estimates to ours come from Abramitzky and Lavy (2014, 2011), which study the high school completion response to a change in the wage returns to schooling in Israeli kibbutzes. Abramitzky and Lavy (2011) argue that the near-zero initial return to schooling in the kibbutz makes a semi-elasticity of high school graduation to a year of schooling more appropriate for understanding the magnitude, and calculate this to be $0.43 .{ }^{34}$ When we calculate the semielasticity to the return to high school from our estimates, we find an average of 0.25 , roughly $60 \%$ of the response in Israel. ${ }^{35}$ Hence a 10 p.p. increase in the return to high school graduation leads to a 2.5 percent increase in high school completion.

Taking these estimates at face value suggests that the response to DACA among undocumented youth may be smaller than among Israeli teens. One potential reason for this is that the perceived wage differences between Mexico, US legal, and US undocumented individuals could be smaller than the ones we calculate. Second, undocumented youth may expect to return to the US if deported, or have lower expectations about the probability of deportation, which would also make the perceived benefit lower than our calculation. Finally, undocumented youth may be less responsive than Israelis because they face other barriers to schooling, such as liquidity constraints, norms about working or helping out at home, or early childbearing, to name a few reasons.

Finally, we note that our analysis has focused on the undocumented population living in the US, holding constant migration decisions, as DACA explicitly required an established presence in the US. However, in the long run, DACA's benefits might encourage new immigration if potential migrants expect the US to continue to pass DACA-like policies. This point, as well as any general equilibrium responses to DACA, are left for future investigation.

\section{Conclusion}

In this paper, we quantify the education response of undocumented youth to a large shock in the returns to education. We obtain variation in the returns to education from the enactment of DACA, which provided temporary deferral from deportation and work authorization to this population. Using a difference-in-difference design, we show that DACA altered the education decisions of undocumented youth.

The policy increased school attendance by 2.2 p.p. and high school graduation rates by 6 p.p., an effect that was more pronounced among Hispanic men. These effects imply that DACA reduced the citizen-non-citizen gap in school attendance by $55 \%$, and the gap in high

\footnotetext{
${ }^{34}$ This is likely to be an upper bound on the elasticity to the change in the return to high school.

${ }^{35}$ See Appendix Table C.3 for the semi-elasticity estimates.
} 
school completion by $40 \%$. We find some increases along the college margin as well, but cannot reject a null effect in our main specification. Auxiliary analyses show that DACA also induced greater effort in school, as we find increases in the pass rates of a mandatory exam for graduation among $12^{\text {th }}$ graders.

These results have significant policy implications. First, they show that a substantial part of the gap in educational attainment between non-citizen and citizen youth is due to the low benefits of schooling associated with lack of legal status. Hence, policies that increase the real or perceived economic opportunities of disadvantaged youth may lead to a more educated workforce. Second, immigration policy is currently at the center of the public debate, with many fearing that undocumented immigrants may bring undesirable attributes to communities, such as low levels of education. Our findings suggest that immigration policies that include incentives for education and reduce uncertainty over employment can lead to improvements in each of these areas of concern. 


\section{References}

Abramitzky, Ran, and Victor Lavy. 2011. "How Responsive is Investment in Schooling to Changes in Redistribution Policies and in Returns." National Bureau of Economic Research Working Paper 17093.

Abramitzky, Ran, and Victor Lavy. 2014. "How responsive is investment in schooling to changes in redistributive policies and in returns?" Econometrica, 82(4): 1241-1272.

Acosta, Yesenia D, Luke J. Larsen, and Elizabeth M. Grieco. 2014. "Noncitizens Under Age 35: 2010-2012." United States Census Bureau.

Agarwal, Sumit, Souphala Chomsisengphet, Neale Mahoney, and Johannes Stroebel. 2015. "Regulating Consumer Financial Products: Evidence from Credit Cards *." The Quarterly Journal of Economics, 130(1): 111-164.

Alsan, Marcella, and Crystal Yang. 2018. "Fear and the Safety Net: Evidence from Secure Communities." National Bureau of Economic Research.

Altonji, Joseph G. 1993. "The demand for and return to education when education outcomes are uncertain." Journal of Labor Economics, 11(1, Part 1): 48-83.

Altonji, Joseph G, Erica Blom, and Costas Meghir. 2012. "Heterogeneity in human capital investments: High school curriculum, college major, and careers." Annu. Rev. Econ., 4(1): 185-223.

Amuedo-Dorantes, Catalina, and Cynthia Bansak. 2006. "Money transfers among banked and unbanked Mexican immigrants." Southern Economic Journal, 374-401.

Amuedo-Dorantes, Catalina, and Francisca Antman. 2016. "Can authorization reduce poverty among undocumented immigrants? Evidence from the Deferred Action for Childhood Arrivals program." Economics Letters, 147: 1-4.

Amuedo-Dorantes, Catalina, and Francisca Antman. 2017. "Schooling and Labor Market Effects of Temporary Authorization: Evidence from DACA." Journal of Population Economics, 30(1): 339-373.

Atkin, David. 2016. "Endogenous Skill Acquisition and Export Manufacturing in Mexico." The American Economic Review, 106(8): 2046-2085.

Bailey, Martha J., and Susan M. Dynarski. 2011. "Inequality in Postsecondary Education." In Whither Opportunity?., ed. Greg J. Duncan and Richard J. Murnane. Russell Sage Foundation.

Baker, Bryan, and Nancy Rytina. 2013. "Estimates of the Unauthorized Immigrant Population Residing in the United States: January 2012." Department of Homeland Security, Office of Immigration Statistics.

Bazzi, Samuel, Sarah Burns, Gordon Hanson, Bryan Roberts, and John Whitley. 2018. "Deterring Illegal Entry: Migrant Sanctions and Recidivism in Border Apprehensions." National Bureau of Economic Research Working Paper 25100.

Becker, Gary Stanley. 1964. Human Capital. University of Chicago Press.

Bernheim, B. Douglas, and Dmitry Taubinsky. 2018. "Behavioral Public Economics." In Handbook of Behavioral Economics - Foundations and Applications 1. Vol. 1 of Handbook of Behavioral Economics: Applications and Foundations 1, , ed. B. Douglas Bernheim, Stefano DellaVigna and David Laibson, 381 516. North-Holland.

Black, Dan A, Terra G McKinnish, and Seth G Sanders. 2005. "Tight labor markets and the demand for education: Evidence from the coal boom and bust." ILR Review, 59(1): 3-16. 
Bleakley, Hoyt, and Aimee Chin. 2010. "Age at arrival, English proficiency, and social assimilation among US immigrants." American Economic Journal. Applied Economics, 2(1): 165.

Borjas, George J. 1985. "Assimilation, changes in cohort quality, and the earnings of immigrants." Journal of Labor Economics, 3(4): 463-489.

Borjas, George J. 2017. "The Earnings of Undocumented Immigrants." National Bureau of Economic Research Working Paper 23236.

Borusyak, Kirill, and Xavier Jaravel. 2016. "Revisiting Event Study Designs."

Cantor, Guillermo, Mark L Noferi, and Daniel Martinez. 2015. "Enforcement Overdrive: A Comprehensive Assessment of ICE's Criminal Alien Program."

Cascio, Elizabeth U, and Ayushi Narayan. 2017. "Who Needs a Fracking Education? The Educational Response to Biased Technological change." Working Paper, Dartmouth College.

Cascio, Elizabeth U, and Ethan G Lewis. 2018. "Distributing the Green (Cards): Permanent Residency and Personal Income Taxes after the Immigration Reform and Control Act of 1986." National Bureau of Economic Research Working Paper 24872.

Charles, Kerwin Kofi, Erik Hurst, and Matthew J. Notowidigdo. 2018. "Housing Booms and Busts, Labor Market Opportunities, and College Attendance." American Economic Review, 108(10): 2947-2994.

Clemens, Michael A., Claudio E. Montenegro, and Lant Pritchett. 2016. "Bounding the Price Equivalent of Migration Barriers." Social Science Research Network SSRN Scholarly Paper ID 2839518, Rochester, NY.

Conley, Timothy G., and Christopher R. Taber. 2010. "Inference with Difference in Differences with a Small Number of Policy Changes." The Review of Economics and Statistics, 93(1): 113-125.

Cortes, Kalena E. 2013. "Achieving the DREAM: The Effect of IRCA on Immigrant Youth Postsecondary Educational Access." American Economic Review, 103(3): 428-432.

Dee, Thomas, and Mark Murphy. 2018. "Vanished Classmates: The Effects of Local Immigration Enforcement on Student Enrollment." National Bureau of Economic Research.

Deming, David, and Susan Dynarski. 2009. "Into College, Out of Poverty? Policies to Increase the Postsecondary Attainment of the Poor." National Bureau of Economic Research Working Paper 15387.

Erisman, Wendy, and Shannon Looney. 2007. "Opening the Door to the American Dream: Increasing Higher Education Access and Success for Immigrants." Institute for Higher Education Policy.

Felfe, Christina, Helmut Rainer, and Judith Saurer. 2016. "Why Birthright Citizenship Matters for Immigrant Children: Impacts on Parental Educational Choices."

Finkelstein, Amy, and Matthew J Notowidigdo. 2018. "Take-up and Targeting: Experimental Evidence from SNAP." National Bureau of Economic Research Working Paper 24652.

Flores, Antonio. 2017. "How the U.S. Hispanic population is changing."

Giuntella, Osea, and Jakub Lonsky. 2018. "The Effects of DACA on Health Insurance, Access to Care, and Health Outcomes."

Goodman-Bacon, Andrew. 2016. "The Long-Run Effects of Childhood Insurance Coverage: Medicaid Implementation, Adult Health, and Labor Market Outcomes." National Bureau of Economic Research Working Paper 22899. 
Hainmueller, Jens, Duncan Lawrence, Linna Martén, Bernard Black, Lucila Figueroa, Michael Hotard, Tomás R. Jiménez, Fernando Mendoza, Maria I. Rodriguez, Jonas J. Swartz, and David D. Laitin. 2017. "Protecting unauthorized immigrant mothers improves their children's mental health." Science.

Hill, Laruen E, and Hans P Johnson. 2011. Unauthorized immigrants in California: Estimates for counties. Public Policy Institute of California.

Hipsman, Faye, Bárbara Gómez-Aguiaga, and Randy Capps. 2016. "DACA at Four: Participation in the Deferred Action Program and Impacts on Recipients."

Hoynes, Hilary, Doug Miller, and David Simon. 2015. "Income, the Earned Income Tax Credit, and Infant Health." American Economic Journal: Economic Policy, 7(1): 172-211.

Hsin, Amy, and Francesc Ortega. 2017. "The Effects of Deferred Action for Childhood Arrivals on the Educational Outcomes of Undocumented Students." IZA Institute of Labor Economics Working Paper 11078.

Jackson, C. Kirabo, Rucker C. Johnson, and Claudia Persico. 2016. "The Effects of School Spending on Educational and Economic Outcomes: Evidence from School Finance Reforms." The Quarterly Journal of Economics, 131(1): 157.

Jayachandran, Seema, and Adriana Lleras-Muney. 2009. "Life Expectancy and Human Capital Investments: Evidence from Maternal Mortality Declines." The Quarterly Journal of Economics, 124(1): 349-397.

Jensen, Robert. 2010. "The (perceived) returns to education and the demand for schooling." The Quarterly Journal of Economics, 125(2): 515-548.

Kaushal, Neeraj. 2006. "Amnesty programs and the labor market outcomes of undocumented workers." Journal of Human Resources, 41(3): 631-647.

Kleven, Henrik Jacobsen, Camille Landais, Emmanuel Saez, and Esben Schultz. 2013. "Migration and wage effects of taxing top earners: Evidence from the foreigners tax scheme in Denmark." The Quarterly Journal of Economics, 129(1): 333-378.

Kossoudji, Sherrie A, and Deborah A Cobb-Clark. 2002. "Coming out of the shadows: Learning about legal status and wages from the legalized population." Journal of Labor Economics, 20(3): 598-628.

Kuka, Elira, Na'ama Shenhav, and Kevin Shih. 2019. "A Reason to Wait: The Effect of Legal Status on Teen Pregnancy." Working Paper.

Lagakos, David, Benjamin Moll, Tommaso Porzio, Nancy Qian, and Todd Schoellman. 2018. "Life Cycle Wage Growth across Countries." Journal of Political Economy, 126(2): 797-849.

LaLonde, Robert J, and Robert H Topel. 1992. "The assimilation of immigrants in the US labor market." In Immigration and the workforce: Economic consequences for the United States and source areas. 67-92. University of Chicago Press.

Lee, Jin Young, and Gary Solon. 2011. "The Fragility of Estimated Effects of Unilateral Divorce Laws on Divorce Rates." The B.E. Journal of Economic Analysis 83 Policy, 11(1).

Liscow, Zachary, and William Gui Woolston. 2016. "Does Legal Status Affect Educational Attainment in Immigrant Families?"

Lopez, Mark Hugo, Jeffrey Passel, and Molly Rohal. 2015. "Chapter 5: U.S. Foreign-Born Population Trends." 
Lopez, Mark Hugo, Paul Taylor, Cary Funk, and Ana Gonzalez-Barrera. 2013. "On Immigration Policy, Deportation Relief Seen As More Important Than Citizenship."

Marie, Olivier, and Ulf Zölitz. 2017. "High Achievers? Cannabis Access and Academic Performance." The Review of Economic Studies, 84(3): 1210-1237.

Mendoza, Gilberto, and Noor Shaikh. 2015. "Tuition benefits for immigrants."

Minnesota Population Center. 2018. "Integrated Public Use Microdata Series, International: Version 7.0."

Murnane, Richard J. 2013. "U.S. High School Graduation Rates: Patterns and Explanations." Journal of Economic Literature, 51(2): 370-422.

Nevarez, Griselda. 2015. "American Dream: After Qualifying For DACA, Young Immigrants Buy Homes."

Olivas, Michael A. 2004. "IIRIRA, the Dream Act, and undocumented college student residency." Immigr. E) Nat'lity L. Rev., 25: 323.

Oreopoulos, Philip, and Kjell G. Salvanes. 2011. "Priceless: The Nonpecuniary Benefits of Schooling." Journal of Economic Perspectives, 25(1): 159-184.

Osili, Una Okonkwo, and Anna L Paulson. 2009. "Immigrants access to financial services and asset accumulation." Insufficient funds: Savings, assets, credit, and banking among low-income households, 285-317.

Oster, Emily, and Bryce Millett Steinberg. 2013. "Do IT service centers promote school enrollment? Evidence from India." Journal of Development Economics, 104: 123-135.

Passel, Jeffrey, and Mark Hugo Lopez. 2012. "Up to 1.7 million unauthorized immigrant youth may benefit from new deportation rules." Washington, DC: Pew Hispanic Center.

Passel, Jeffrey S. 2003. "Further demographic information relating to the DREAM Act." Washington, DC: The Urban Institute.

Passel, Jeffrey S. 2005. "Estimates of the Size and Characteristics of the Undocumented Population."

Passel, Jeffrey S., and D'Vera Cohn. 2009. "A Portrait of Unauthorized Immigrants in the United States."

Passel, Jeffrey S., and D’Vera Cohn. 2014. "Chapter 2: Birthplaces of U.S. Unauthorized Immigrants."

Pope, Nolan G. 2016. "The Effects of DACAmentation: The Impact of Deferred Action for Childhood Arrivals on Unauthorized Immigrants." Journal of Public Economics, 143: 98-114.

Redstone, Ilana, and Douglas S. Massey. 2004. "Coming To Stay: An Analysis of the U.S. Census Question On Immigrants Year of Arrival." Demography, 41(4): 721-738.

Rivera-Batiz, Francisco L. 1999. "Undocumented workers in the labor market: An analysis of the earnings of legal and illegal Mexican immigrants in the United States." Journal of Population Economics, 12(1): 91116.

Ruggles, Steven, Katie Genadek, Ronald Goeken, Josiah Grover, and Matthew Sobek. 2017. "Integrated Public Use Microdata Series: Version 7.0." University of Minnesota, Minneapolis.

Shah, Manisha, and Bryce Millett Steinberg. 2017. "Drought of Opportunities: Contemporaneous and LongTerm Impacts of Rainfall Shocks on Human Capital." Journal of Political Economy, 125(2): 527-561.

Simanski, John F., and Lesley Sapp. 2012. "Immigration Enforcement Actions: 2012." Department of Homeland Security. 
Singer, Audrey, Nicole Prchal Svajlenka, and Jill H Wilson. 2015. "Local Insights From DACA for Implementing Future Programs for Unauthorized Immigrants."

Vargas, Jose Antonio. 2012. "How Obamas New Policy Affects Undocumented Youth - and Me." Time.

Watson, Tara. 2013. "Enforcement and immigrant location choice." National Bureau of Economic Research.

Wiswall, Matthew, and Basit Zafar. 2014. "Determinants of college major choice: Identification using an information experiment." The Review of Economic Studies, 82(2): 791-824.

Wolfers, Justin. 2006. "Did Unilateral Divorce Laws Raise Divorce Rates? A Reconciliation and New Results." American Economic Review, 96(5): 1802-1820.

Wong, Tom K., Greisa Martinez Rosas, Adrian Reyna, Ignacia Rodriguez, Patrick OShea, Tom Jawetz, and Philip E. Wolgin. 2016. "New Study of DACA Beneficiaries Shows Positive Economic and Educational Outcomes." 


\section{Figures}

Figure 1: DACA Applications - Years 2011-2016

(a) Initial DACA Applications and Approvals by Quarter

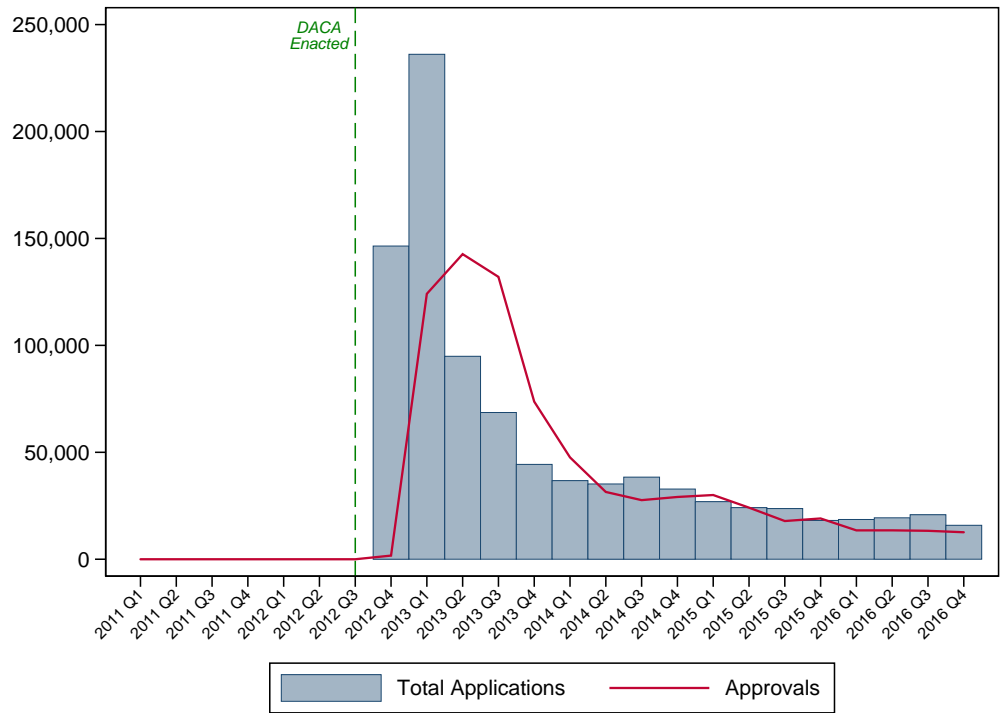

(b) Cumulative Initial DACA Applications by State as of Q4 2016

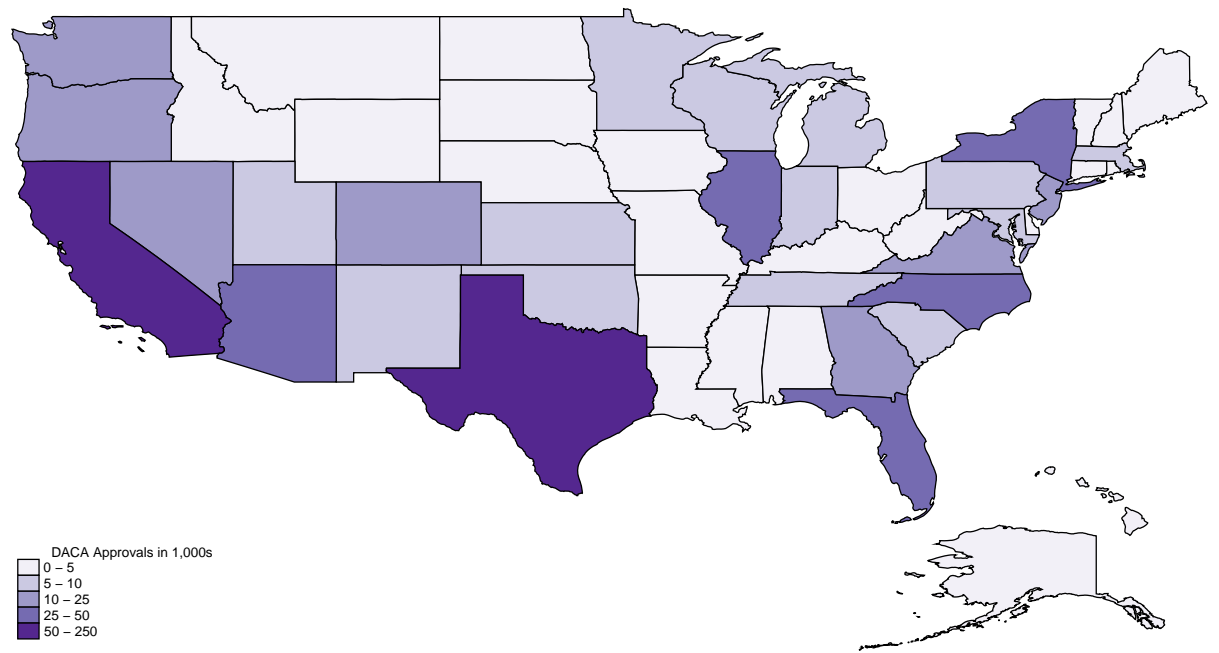

Notes: Figure (a) shows first-time DACA application counts and the number approved in each quarter through 2016. Figure (b) shows first-time DACA application counts across states as of the fourth quarter of 2016. Data comes from publicly available records from United States Citizenship and Immigration Services. See https://www.uscis.gov/tools/reports-studies/immigration-forms-data/data-setform-i-821d-deferred-action-childhood-arrivals. 
Figure 2: Average School Attendance and High School Completion, Hispanics

(a) School Attendance, Ages 14-18

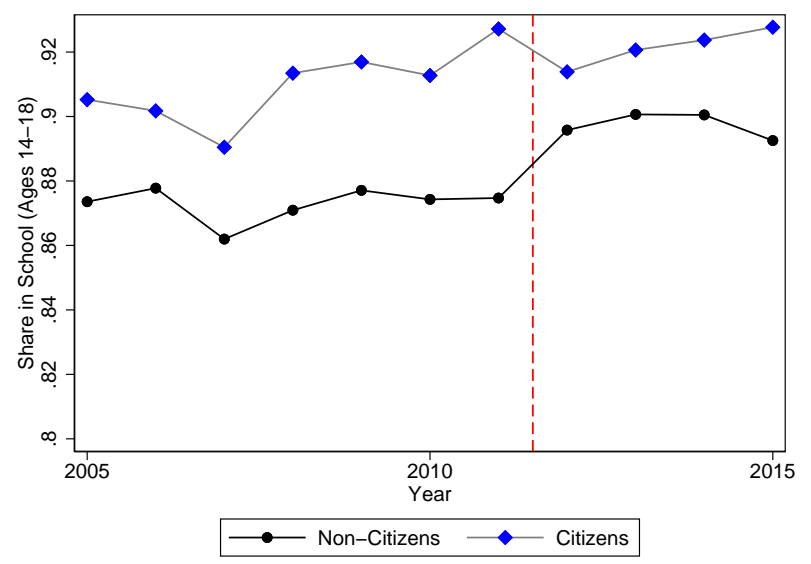

(b) High School Completion, Ages 19-22

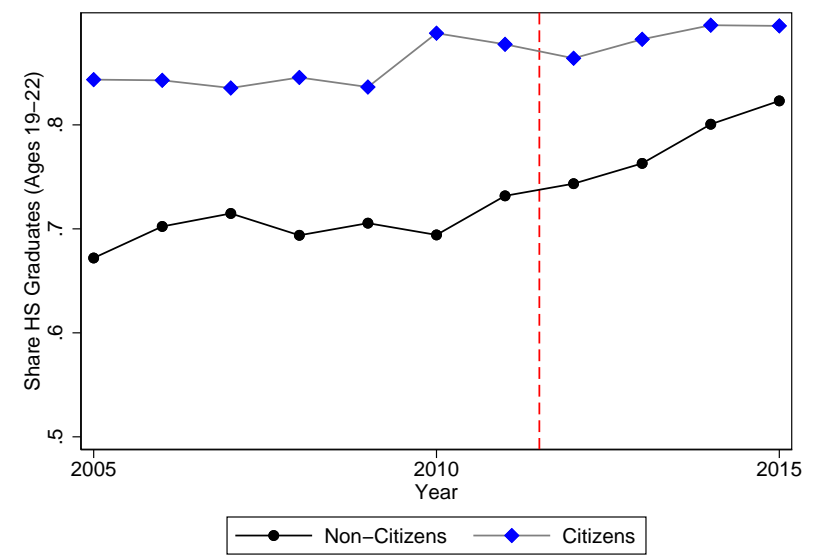

Notes: This figure shows the average school attendance and high school completion rates for Hispanic immigrants ages 14-18 and ages 19-22 for eligible youth (non-citizens) and non-eligible youth (citizens). The vertical dashed line demarcates the implementation of DACA. Data: 2005-2015 American Community Survey. Sample is composed of foreign born Hispanics who immigrated by age 10 and by 2007 . 
Figure 3: Effect of DACA on School Attendance, Ages 14-18

(a) All

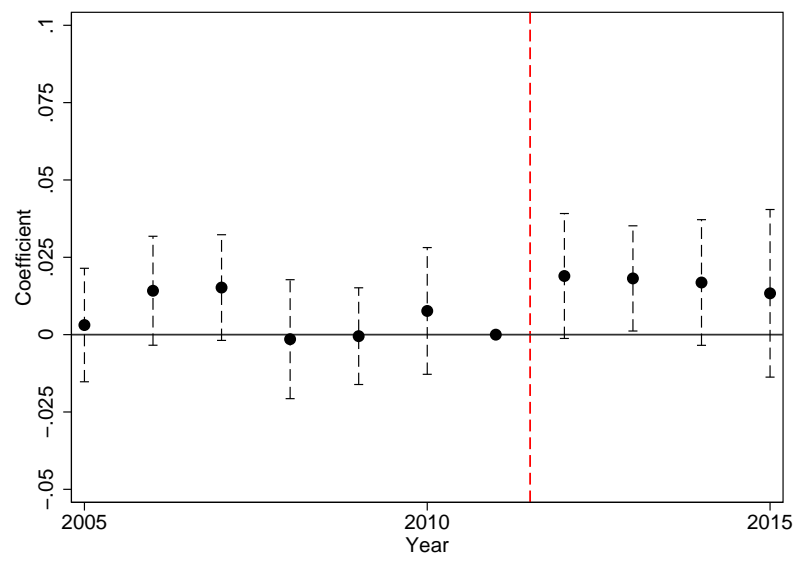

(b) Hispanic

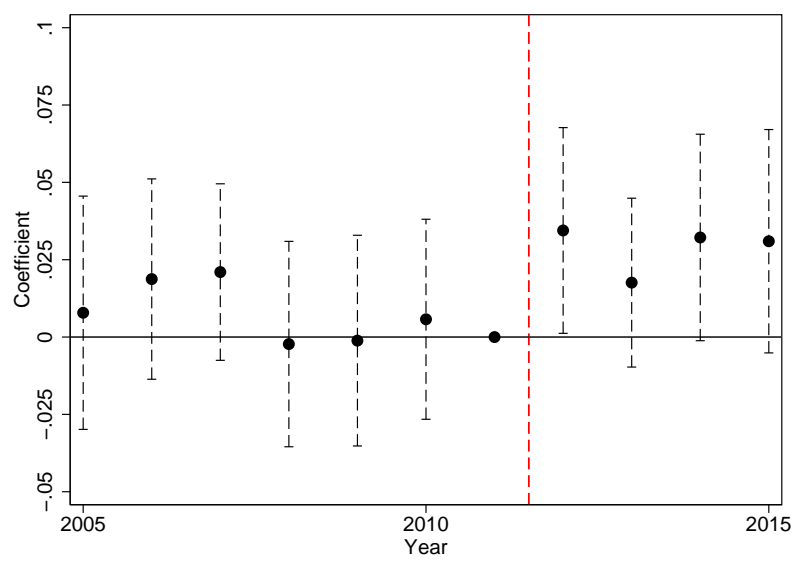

(c) High Take-Up

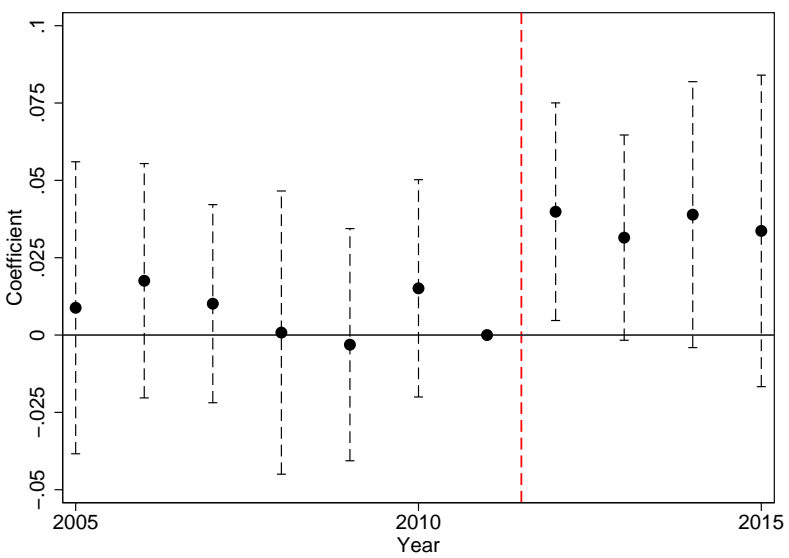

Notes: These figures shows the coefficients and $95 \%$ confidence intervals from event study regressions that estimate interactions between year and eligibility indicators, where the outcomes is an indicator for being in school, and year 2011 is the omitted category. The dashed vertical line indicates the enactment of DACA. Eligible individuals are defined as non-citizen immigrants, and the comparison group is comprised of citizen immigrants. All regressions control for the following fixed effects: sex, year of immigration, birth region, age of immigration-by-eligibility, age-by-eligibility, state-by-year, race-by-year, and age-by-year (see Equation 1). Standard errors are clustered by state, and regressions are weighted by the survey sampling weights. High take-up includes individuals born in countries that have a DACA-eligible take-up rate above $30 \%$ - see text for details. Data: 2005-2015 American Community Survey (ACS). Sample is composed of foreign born Hispanics between the ages of 14 and 18 who immigrated by age 10 and by 2007 . 
Figure 4: Effect of DACA on High School Completion, Age 19-22

(a) All

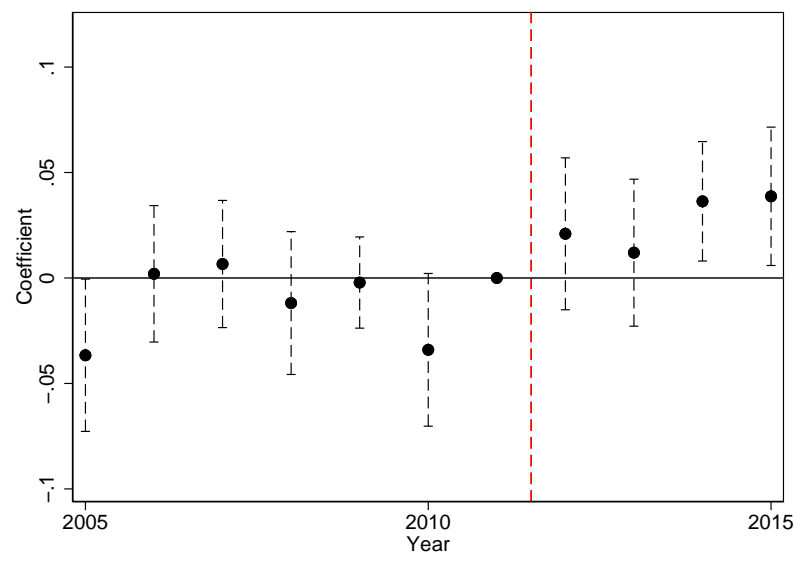

(b) Hispanic

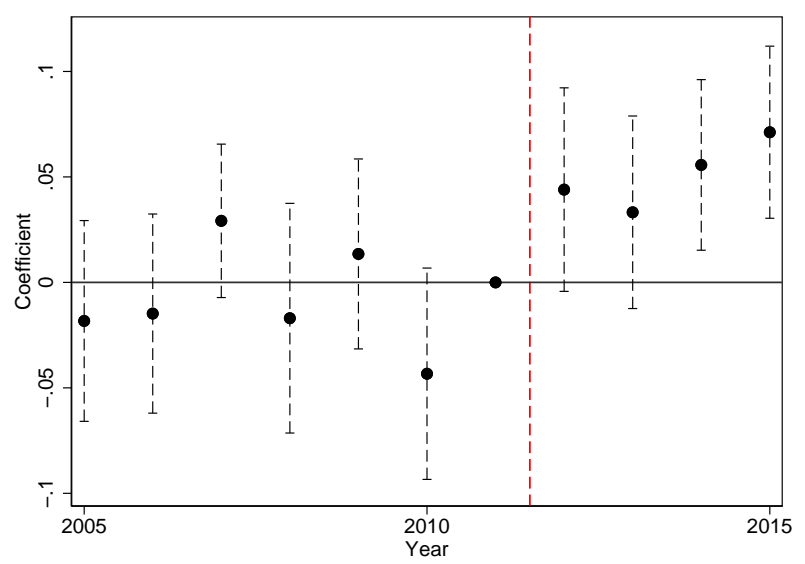

(c) High Take-Up

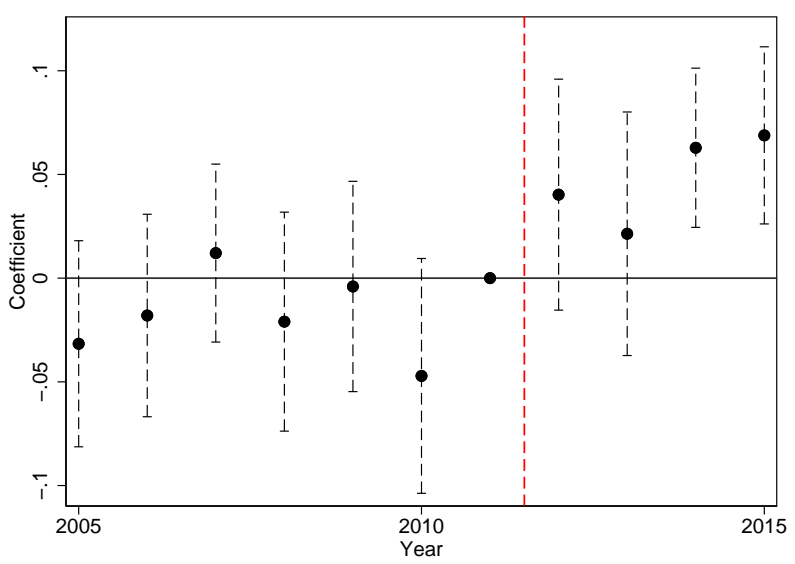

Notes: These figures show the coefficients and $95 \%$ confidence intervals from event study regressions that estimate interactions between year and eligibility indicators, where the outcomes is an indicator for being in school between the ages of 19 and 22 , and year 2011 is the omitted category. The dashed vertical line indicates the enactment of DACA. See the notes accompanying Figure 3 for definition of eligibility, control variables, clustering, sample weights, and high take-up. Data: 2005-2015 American Community Survey. Sample is composed of foreign born Hispanics between the ages of 19 and 22 who immigrated by age 10 and by 2007 . 
Figure 5: Permutation Tests of School Attendance and High School Completion, Hispanics

(a) School Attendance, Ages 14-18

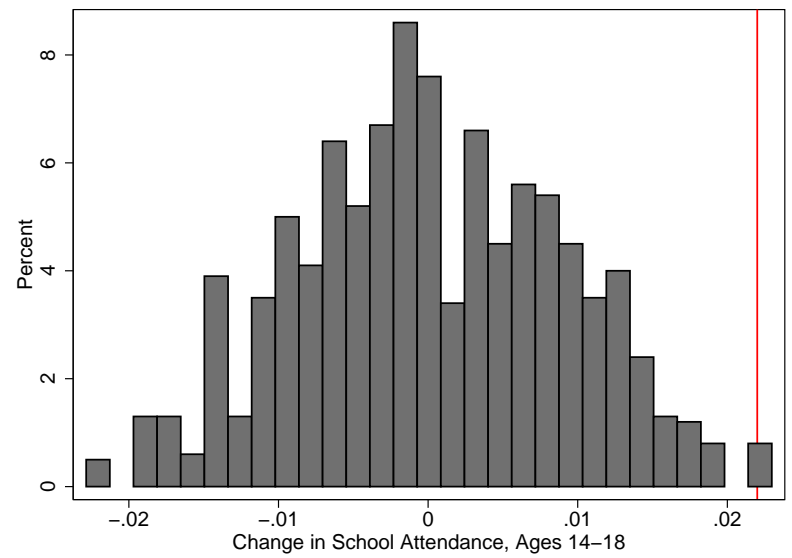

(b) High School Completion, Ages 19-22

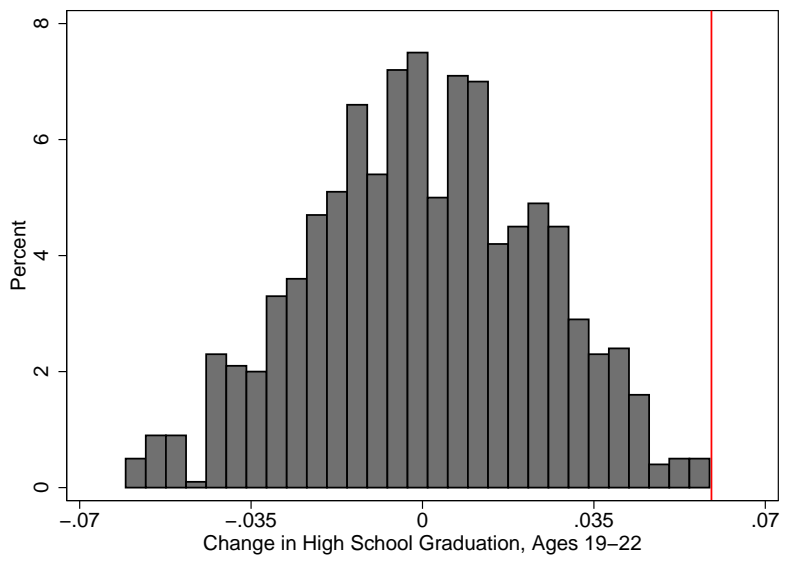

Notes: These figures show results from permutation tests where we compare our estimated effect of DACA for the Hispanic sample to placebo estimates from 1,000 samples where we randomly assign four years as "treated", and the remaining seven years as the pre-period. We plot the distribution of placebo estimates, with our estimated effect represented by the vertical red line. See the notes of Figure 3 for definition of eligibility, control variables, clustering, and sample weights. The implied p-values are less than 0.01 for both panels. Data: 2005-2015 American Community Survey. Sample is composed of foreign born Hispanics ages 14-18 (Panel A) or 19-22 (Panel B) who immigrated by age 10 and by 2007. 
Figure 6: Effect of DACA on High School Attendance, California

(a) High School Enrollment

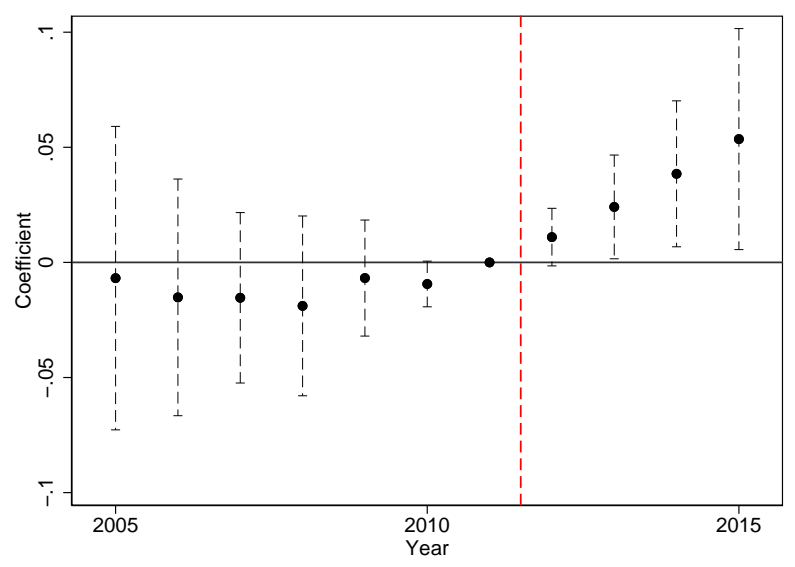

(b) Math Test Takers

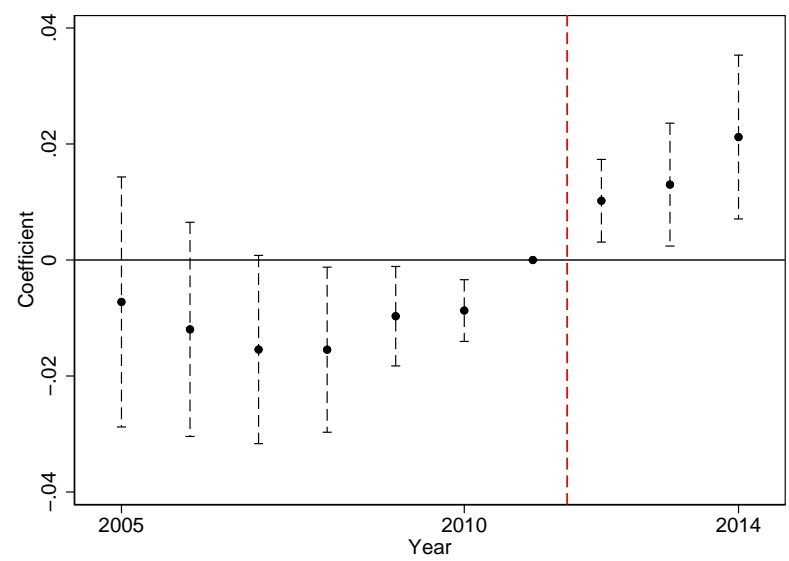

(c) ELA Test Takers

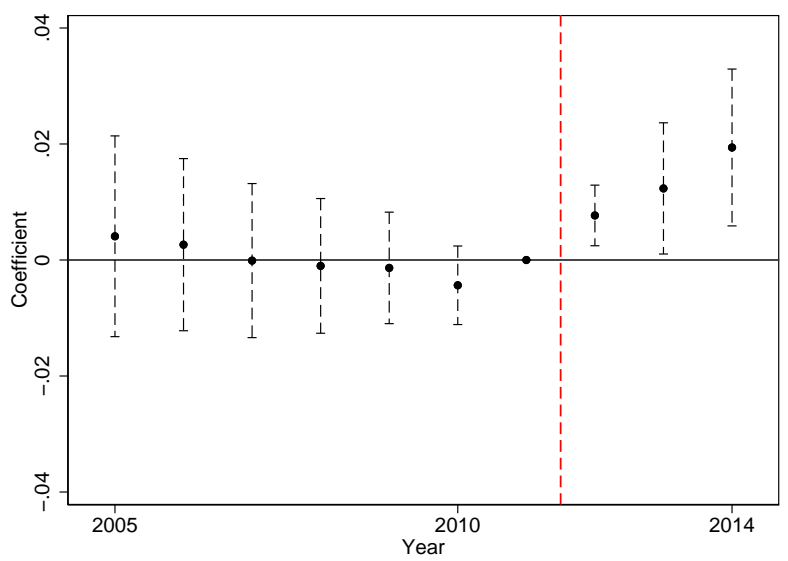

Notes: These figures show event study regressions that separately estimate interactions between year and an indicator for being a county with an above median share of DACA-eligible Hispanics, where year 2011 is the omitted category. The outcomes are the share of youth that are (i) enrolled in high school (Panel A); (ii) sat for the Math CAHSEE (Panel B); or (iii) sat for the ELA CAHSEE (Panel C). The denominator for the shares is the average number of Hispanics aged 14 to 18 in the county between 2005-2011. Regressions include county fixed effects, year fixed effects, and control for the county unemployment rate (See Equation 2). Regressions are weighted by the average number of Hispanics aged 14 to 18 in the county in the 2005-2011 ACS, and standard errors are clustered by county. The difference-in-differences estimate is $0.042(p=0.108)$ for enrollment, $0.024(p<0.01)$ for math test-takers is and $0.013(p<0.10)$ for ELA test-takers. Data: Enrollment data for academic years 2005/06 to 2015/16) and CAHSEE data for 2005/06 to 2015/16, provided by the California Department of Education. 


\section{Tables}

Table 1: Effect of DACA on School Attendance

\begin{tabular}{lccc}
\hline \hline & All & Hispanic & High Take-Up \\
\hline \hline A: Age 14-18 & & & \\
\hline Eligible*Post & $0.012^{* *}$ & $0.022^{* * *}$ & $0.029^{* * *}$ \\
& $(0.005)$ & $(0.008)$ & $(0.008)$ \\
\hline Mean Y & 0.921 & 0.891 & 0.889 \\
Individuals & 114453 & 54015 & 48359 \\
\hline B: Age 19-22 & & & \\
Eligible*Post & 0.019 & 0.020 & 0.005 \\
& $(0.012)$ & $(0.014)$ & $(0.012)$ \\
\hline Mean Y & 0.547 & 0.405 & 0.401 \\
Individuals & 82077 & 38704 & 34768 \\
\hline \hline
\end{tabular}

Notes: This table shows the difference-in-difference estimates of the impact of DACA on the school attendance of eligible youth. Eligible individuals are defined as non-citizen immigrants, and the comparison group is comprised of citizen immigrants. High take-up includes individuals born in countries that have a DACA-eligible take-up rate above $30 \%$ - see text for details. The outcome is current school attendance, and post is an indicator for 2012 or after. All regressions control for the following fixed effects: sex, year of immigration, birth region, age of immigration-by-eligibility, age-by-eligibility, state-byyear, race-by-year, and age-by-year (see Equation 1). Standard errors, shown in parentheses, are clustered by state, and regressions are weighted by the survey sampling weights. $* \mathrm{p}<0.10, * * \mathrm{p}<0.05, * * *$ $\mathrm{p}<0.01$. Data: 2005-2015 American Community Survey. Sample is composed of foreign born individuals ages 14-18 (Panel A) or 19 to 22 (Panel B) who immigrated by age 10 and by 2007 . 
Table 2: Effect of DACA on High School Completion and College Enrollment

\begin{tabular}{|c|c|c|c|c|c|c|}
\hline & \multicolumn{3}{|c|}{ "High School Completion } & \multicolumn{3}{|c|}{ Some College } \\
\hline & All & Hispanic & $\overline{\text { High Take-Up }}$ & All & Hispanic & High Take-Up \\
\hline \multicolumn{7}{|l|}{ A: Age 19} \\
\hline$\overline{\text { Eligible*Post }}$ & $\begin{array}{c}0.046^{* * *} \\
(0.016)\end{array}$ & $\begin{array}{l}0.065^{* *} \\
(0.026)\end{array}$ & $\begin{array}{c}0.085^{* * *} \\
(0.027)\end{array}$ & $\begin{array}{c}0.003 \\
(0.025)\end{array}$ & $\begin{array}{c}0.034 \\
(0.029)\end{array}$ & $\begin{array}{l}0.057^{* *} \\
(0.028)\end{array}$ \\
\hline Mean Y & 0.824 & 0.747 & 0.741 & 0.468 & 0.350 & 0.343 \\
\hline Individuals & 22153 & 10252 & 9173 & 22153 & 10252 & 9173 \\
\hline \multicolumn{7}{|l|}{ B: Age 19-22 } \\
\hline$\overline{\text { Eligible*Post }}$ & $\begin{array}{c}0.038^{* * *} \\
(0.007)\end{array}$ & $\begin{array}{c}0.059^{* * *} \\
(0.010)\end{array}$ & $\begin{array}{c}0.064^{* * *} \\
(0.011)\end{array}$ & $\begin{array}{c}0.017^{*} \\
(0.009)\end{array}$ & $\begin{array}{c}0.013 \\
(0.010)\end{array}$ & $\begin{array}{c}0.011 \\
(0.011)\end{array}$ \\
\hline Mean Y & 0.858 & 0.781 & 0.775 & 0.544 & 0.407 & 0.399 \\
\hline Individuals & 82077 & 38704 & 34768 & 82077 & 38704 & 34768 \\
\hline \multicolumn{7}{|l|}{ C: Age 23-30 } \\
\hline$\overline{\text { Eligible*Post }}$ & $\begin{array}{l}0.013^{* *} \\
(0.005)\end{array}$ & $\begin{array}{l}0.015^{*} \\
(0.008)\end{array}$ & $\begin{array}{c}0.013 \\
(0.008)\end{array}$ & $\begin{array}{c}0.008 \\
(0.009)\end{array}$ & $\begin{array}{l}-0.001 \\
(0.010)\end{array}$ & $\begin{array}{l}-0.000 \\
(0.010)\end{array}$ \\
\hline Mean Y & 0.862 & 0.767 & 0.761 & 0.613 & 0.443 & 0.435 \\
\hline Individuals & 133576 & 61210 & 54110 & 133576 & 61210 & 54110 \\
\hline
\end{tabular}

Notes: This table shows the difference-in-difference estimates of the impact of DACA on the high school completion and the attainment of some college of eligible youth. The outcomes are high school completion (GED or diploma) in Columns 1-3, and completion of some college (more than 12 years of completed education) in Columns 4-6, and post is an indicator for 2012 or after. See the notes of Table 1 for the definition of eligibility, high take-up, control variables, clustering, and sample weights. ${ }^{*} \mathrm{p}<0.10,{ }^{* *} \mathrm{p}<0.05,{ }^{* * *} \mathrm{p}<0.01$. Data: 20052015 American Community Survey. Sample is composed of foreign born individuals ages 19 (Panel A) or 19-22 (Panel B) or 23-30 (Panel C) who immigrated by age 10 and by 2007. 
Table 3: Effect of DACA on Main Outcomes, Hispanics - Alternative Sample Restrictions

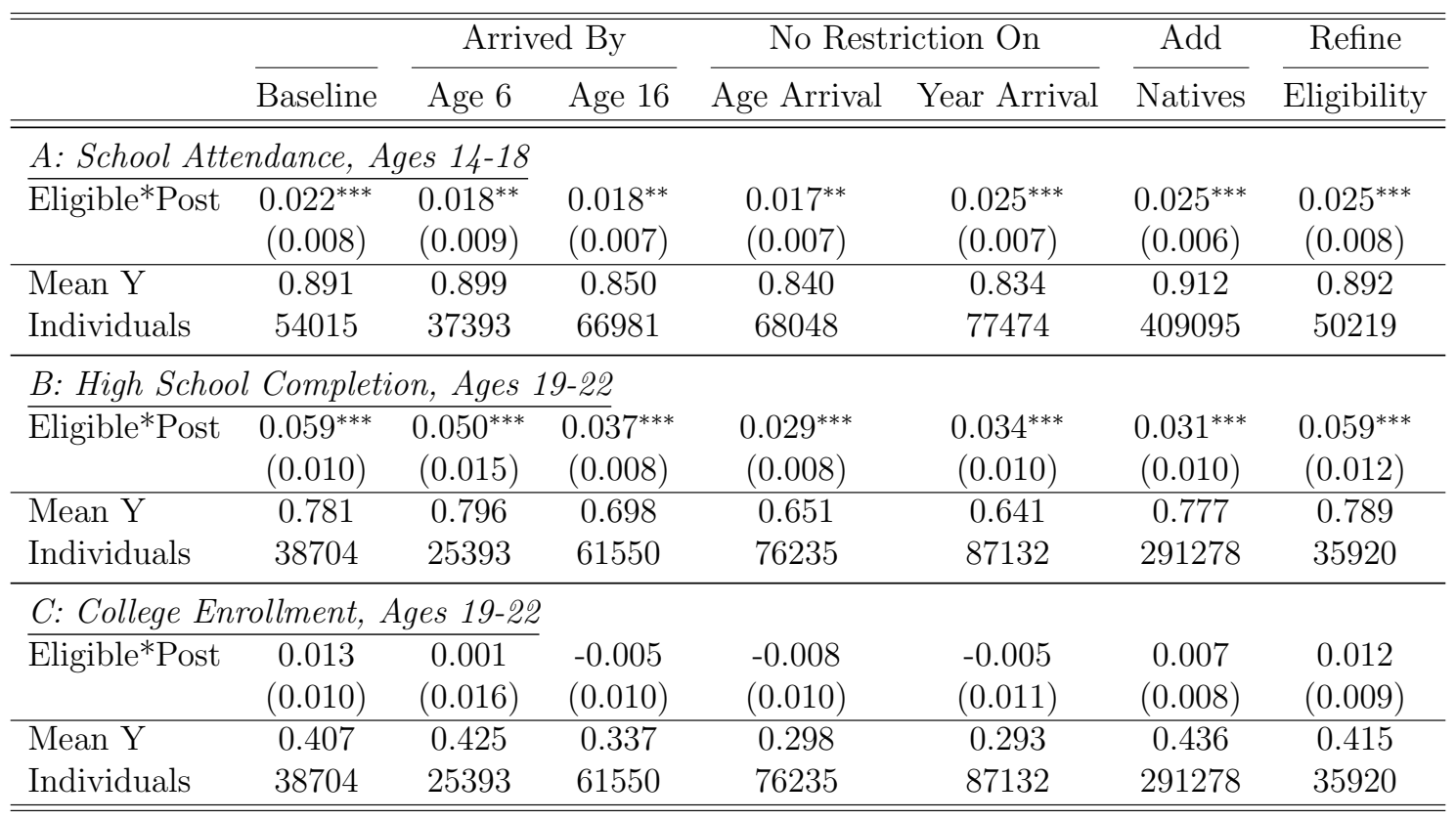

Notes: This table shows difference-in-differences estimates of the impact of DACA on schooling decisions of eligible youth, with different restrictions. Column (1) contains baseline results from Tables 1 and 2. Columns (2) and (3) adjust the sample to include only individuals who arrived by age 6 (more restrictive) and by 16 (more expansive), respectively. Column (4) adds to the comparison group foreign born individuals who arrived after age 16; (5) adds foreign born individuals who arrived after 2007; and (6) adds individuals born in the US. Column (7) refines the baseline specification, restricting eligibility to individuals that do not live in a household that receives government benefits or that has a veteran in it. The dependent variable is shown in the panel heading, and post is an indicator for 2012 or after. See the notes of Table 1 for the definition of eligibility, high take-up, control variables, clustering, and sample weights. ${ }^{*} \mathrm{p}<0.10,{ }^{* *} \mathrm{p}<0.05,{ }^{* * *} \mathrm{p}<0.01$. Data: 2005-2015 American Community Survey. Sample composed of Hispanics ages 14-18 or ages 19-22. 
Table 4: Effect of DACA on High School Completion and College Enrollment, Ages 19-22 - By Sex

\begin{tabular}{|c|c|c|c|c|c|c|}
\hline & \multicolumn{3}{|c|}{ High School Completion } & \multicolumn{3}{|c|}{ Some College } \\
\hline & All & Female & Male & All & Female & Male \\
\hline \multicolumn{7}{|l|}{ A: Hispanic } \\
\hline \multirow[t]{2}{*}{$\overline{\text { Eligible*Post }}$} & $0.059^{* * *}$ & $0.035^{* *}$ & $0.077^{* * *}$ & 0.013 & 0.009 & 0.015 \\
\hline & $(0.010)$ & $(0.014)$ & $(0.016)$ & $(0.010)$ & $(0.017)$ & $(0.018)$ \\
\hline Mean Y & 0.781 & 0.812 & 0.754 & 0.407 & 0.456 & 0.363 \\
\hline P-val. Male $=$ Fem & & & 0.07 & & & 0.84 \\
\hline Individuals & 38704 & 18501 & 20203 & 38704 & 18501 & 20203 \\
\hline \multicolumn{7}{|l|}{ B: High Take-Up } \\
\hline \multirow[t]{2}{*}{ Eligible*Post } & $0.064^{* * *}$ & $0.040^{* * *}$ & $0.084^{* * *}$ & 0.011 & 0.004 & 0.014 \\
\hline & $(0.011)$ & $(0.013)$ & $(0.019)$ & $(0.011)$ & $(0.013)$ & $(0.018)$ \\
\hline Mean Y & 0.775 & 0.806 & 0.747 & 0.399 & 0.446 & 0.357 \\
\hline P-val. Male $=$ Fem & & & 0.09 & & & 0.66 \\
\hline Individuals & 34768 & 16574 & 18194 & 34768 & 16574 & 18194 \\
\hline
\end{tabular}

Notes: This table shows the difference-in-difference estimates of the impact of DACA on the high school completion and the attainment of some college of eligible youth ages 19-22. The outcomes are high school completion (GED or diploma) in Columns 1-3, and completion of some college (more than 12 years of completed education) in Columns 4-6, and post is an indicator for 2012 or after. See the notes of Table 1 for the definition of eligibility, high take-up, control variables, clustering, and sample weights. ${ }^{*} \mathrm{p}<0.10,{ }^{* *} \mathrm{p}<0.05$, ${ }^{* * *} \mathrm{p}<0.01$. Data: 2005-2015 American Community Survey. Sample is composed of foreign born individuals ages 19-22 who immigrated by age 10 and by 2007 . 
Table 5: Implied Elasticity of High School Graduation to Wages

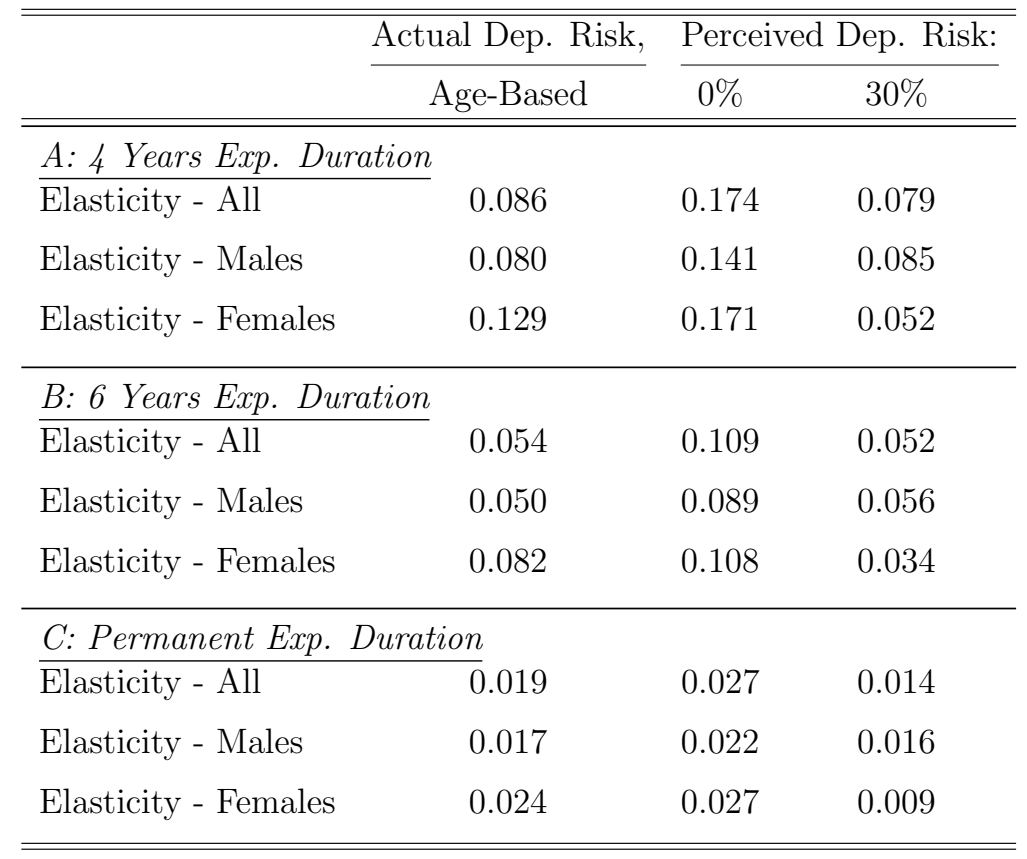

Notes: Estimates of the elasticity of high school for all, males, and female DACAeligible youth, under various expectations of the duration of DACA (4 years, 6 years, and permanent) and the deportation risk. Elasticity calculated using (1) the implied ITT effects of DACA for Hispanics (see Section 8) and (2) estimates of the wage benefits of DACA using inputs from Table C.1 together with the framework for expected wages in Section C. 


\section{A Supplementary Tables and Figures}

Figure A.1: Trends in School Attendance Among Non-Chosen Comparison Groups, Hispanic Immigrant Non-Citizens Ages 14-18

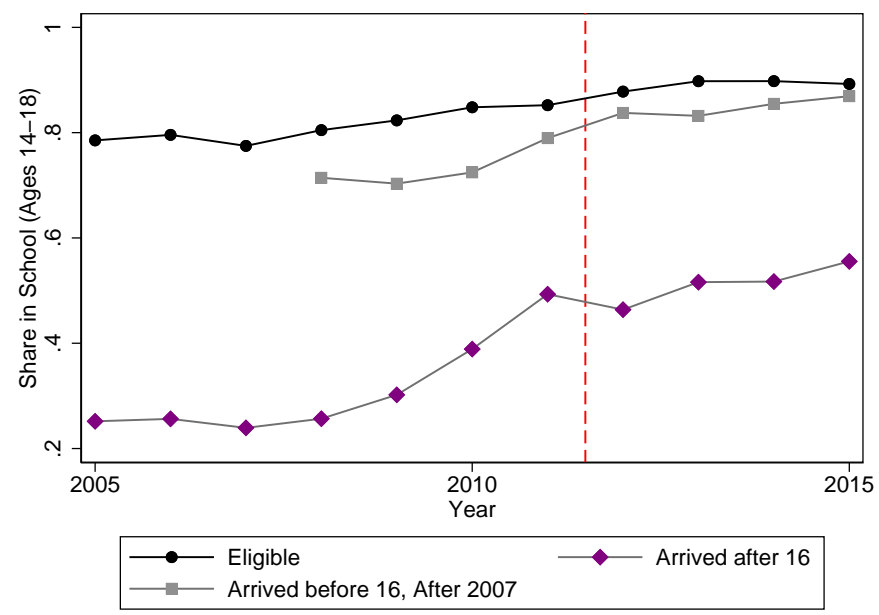

Notes: This figure shows school attendance rates for Hispanic immigrant non-citizens aged $14-18$ who immigrated by age 10 and by 2007 , or who immigrated after 16 or 2007, calculated from the 2005-2015 American Community Surveys. The vertical dashed line indicates the implementation of DACA.

Figure A.2: Effect of DACA on Predicted School Attendance and

High School Completion, Hispanics

(a) School Attendance, Ages 14-18

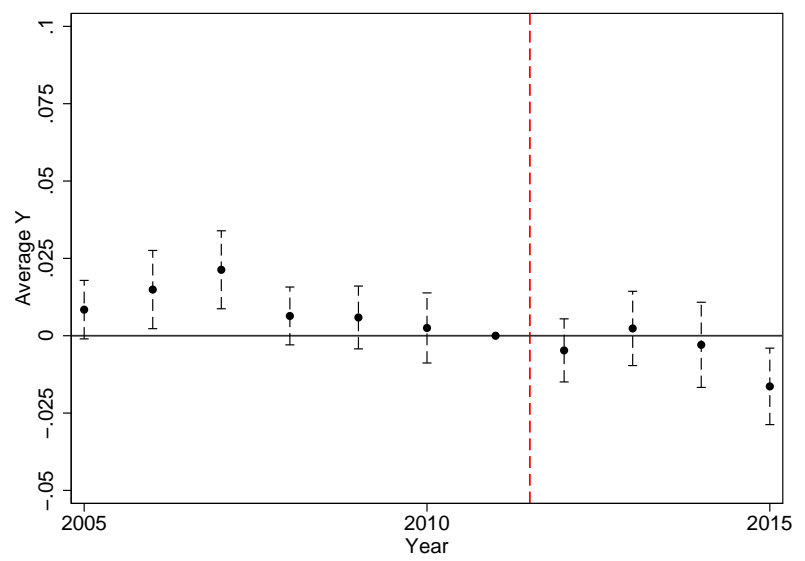

(b) High School Completion, Ages 19-22

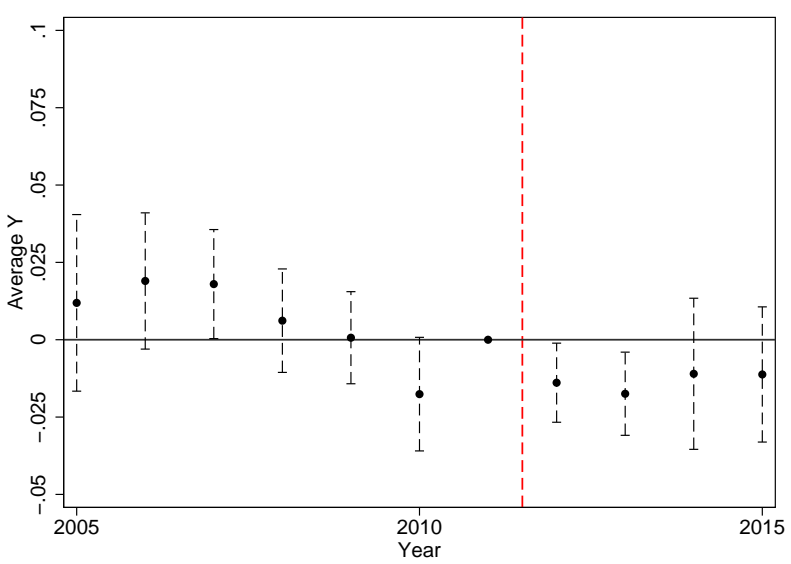

Notes: This figure shows the coefficients and 95\% confidence intervals from event study regressions that estimate interactions between year and eligibility indicators, where the outcomes are predicted schooling outcomes, and year 2011 is the omitted category. The outcomes are the fitted values of likelihood of being in school (Panel A) and high school completion (Panel B), obtained from regressions of observed schooling outcomes on indicators for age, race, sex, age and year of immigration, citizenship status, birthplace, language, state, metropolitan status, health insurance coverage, presence of mother and father in the household, parental college attendance, family size, number of siblings, household poverty status, and the presence of a food stamp recipient in the household using data from 2005 to 2011. See the notes of Figure 3 for definition of eligibility, control variables, clustering, and sample weights. Data: 2005-2015 American Community Survey. Sample is composed of foreign born Hispanics who immigrated by age 10 and by 2007. 
Figure A.3: Effect of DACA on School Attendance, Ages 19-22

(a) All

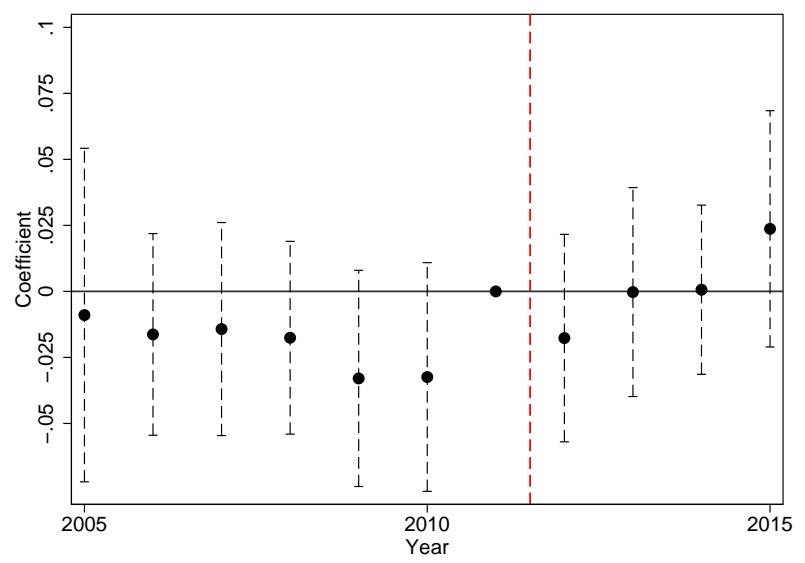

(b) Hispanic

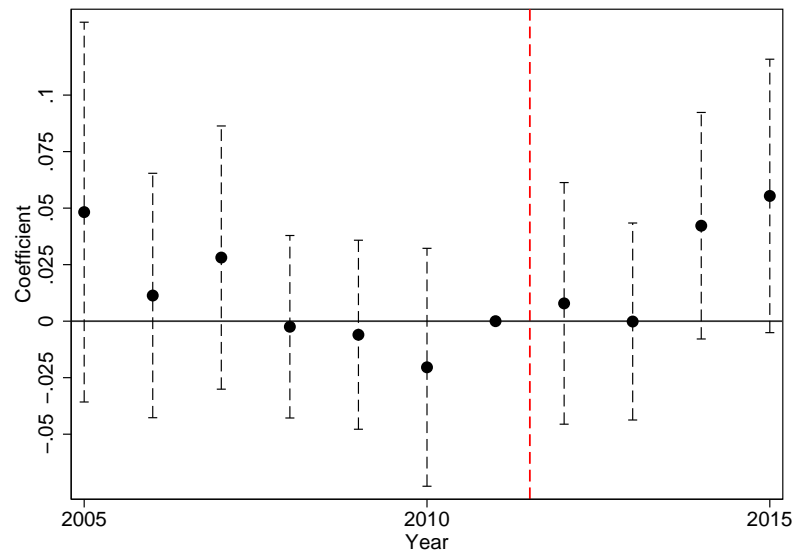

(c) High Take-Up

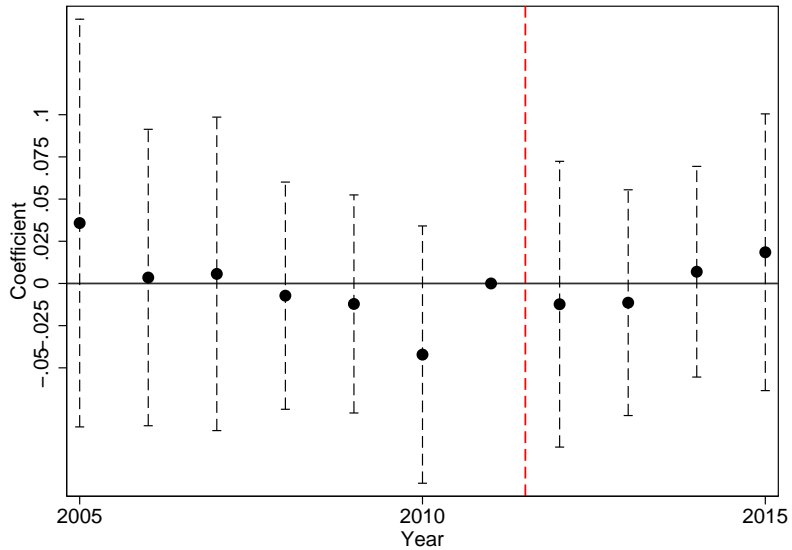

Notes: This figure shows the coefficients and 95\% confidence intervals from event study regressions that estimate interactions between year and eligibility indicators, where the outcomes is school attendance during ages 19-22, and year 2011 is the omitted category. The dashed vertical line indicates the enactment of DACA. See the notes of Figure 3 for definition of eligibility, control variables, clustering, sample weights, and high take-up. Data: 2005-2015 American Community Survey. Sample is composed of foreign born Hispanics ages 19-22 who immigrated by age 10 and by 2007 . 
Figure A.4: Effect of DACA on College Enrollment, Ages 19-22

(a) All

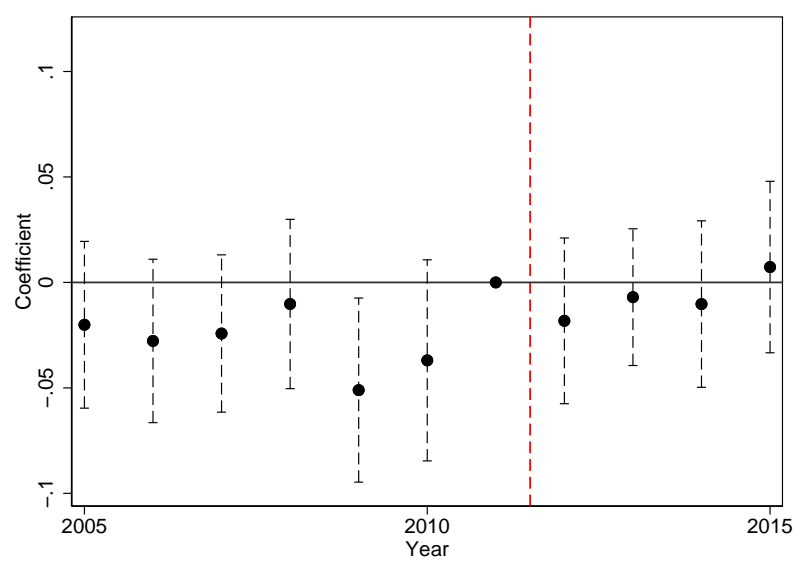

(b) Hispanic

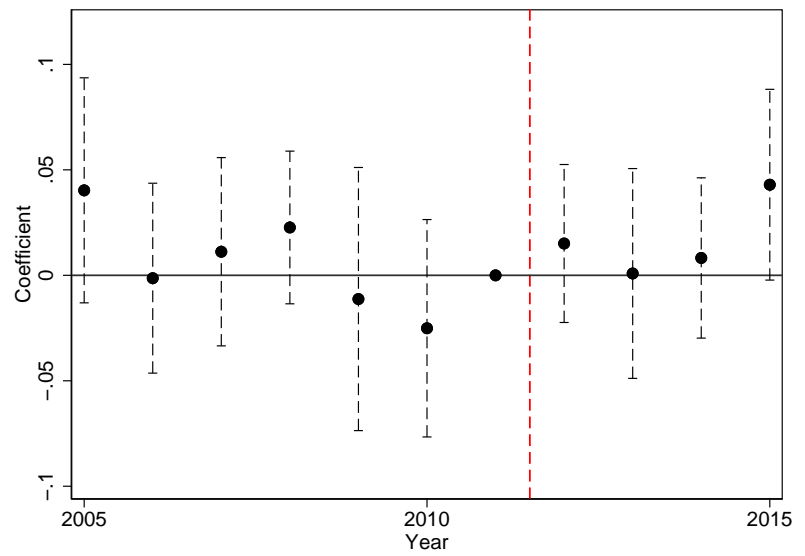

(c) High Take-Up

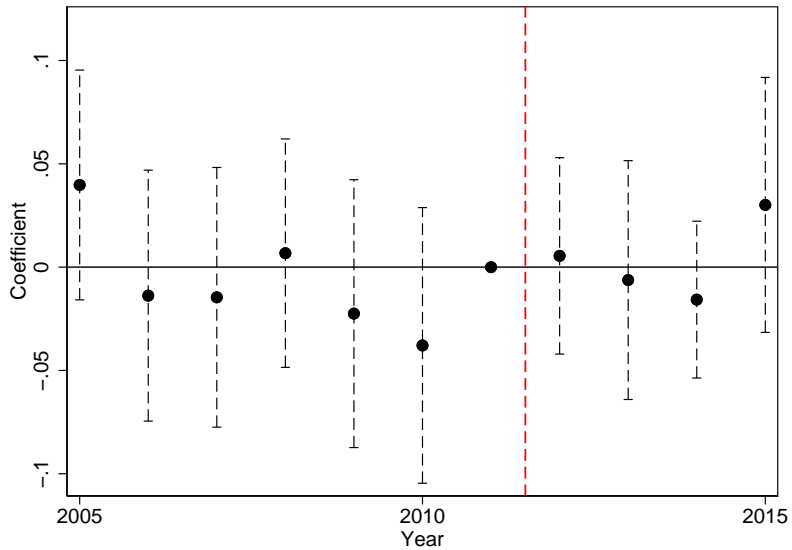

Notes: This figure shows the coefficients and 95\% confidence intervals from event study regressions that estimate interactions between year and eligibility indicators, where the outcome is attainment of some college (more than 12 years of completed education), and year 2011 is the omitted category. The dashed vertical line indicates the enactment of DACA. See the notes of Figure 3 for definition of eligibility, control variables, clustering, sample weights, and high take-up. Data: 2005-2015 American Community Survey. Sample is composed of foreign born Hispanics ages 19-22 who immigrated by age 10 and by 2007 . 
Figure A.5: Impact of DACA on School Attendance, Ages 14-18 Controlling for Secure Communities

(a) Hispanic

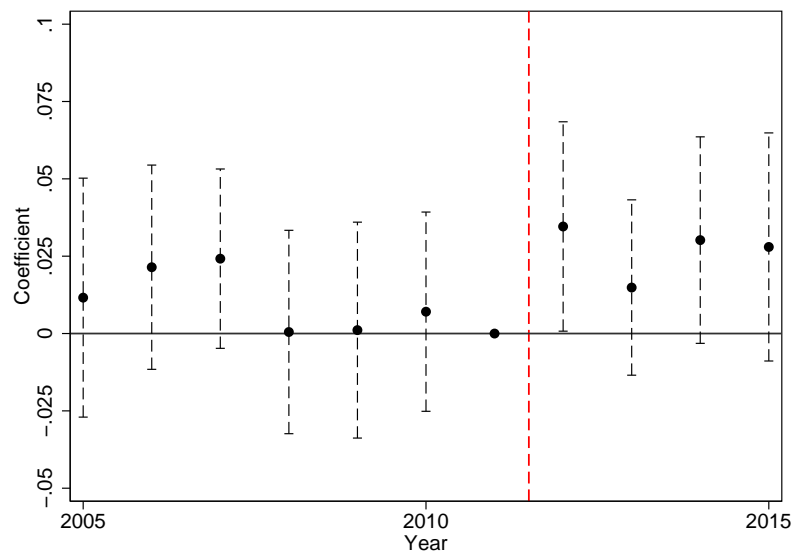

(b) High Take-Up

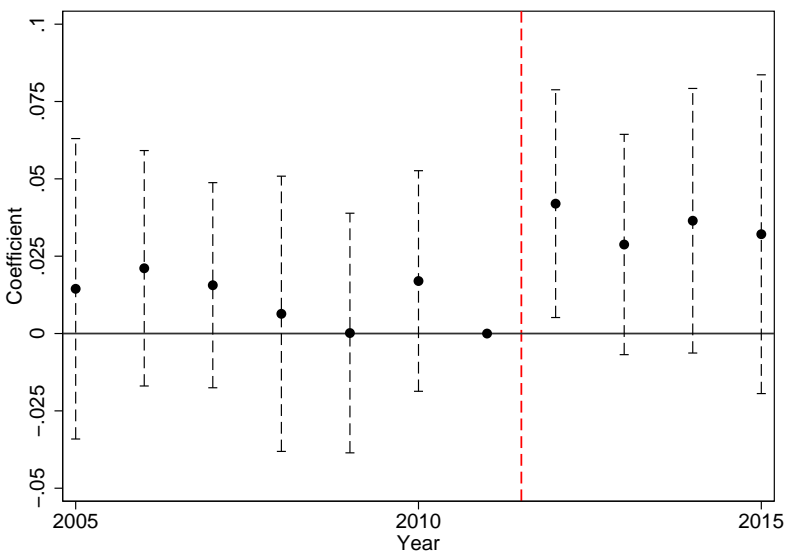

Notes: This figure shows the coefficients and 95\% confidence intervals from event study regressions that estimate interactions between year and eligibility indicators, where the outcome is school attendance between ages 14-18, and year 2011 is the omitted category. The dashed vertical line indicates the enactment of DACA. We include controls for the presence of Secure Communities in the county in addition to the following fixed effects: sex, year of immigration, birth region, age of immigration-by-eligibility, age-by-eligibility, state-by-year, race-by-year, and age-by-year (see Equation 1). See the notes of Figure 3 for definition of eligibility, clustering, sample weights, and high take-up. Data: 2005-2015 American Community Survey. Sample is composed of foreign born ages 14-18 who immigrated by age 10 and by 2007. Data on Secure Community activation dates by county were provided by Alsan and Yang (2018). 
Table A.1: Pre-DACA Characteristics of Hispanic Treatment and

Comparison Groups, Ages 14-22

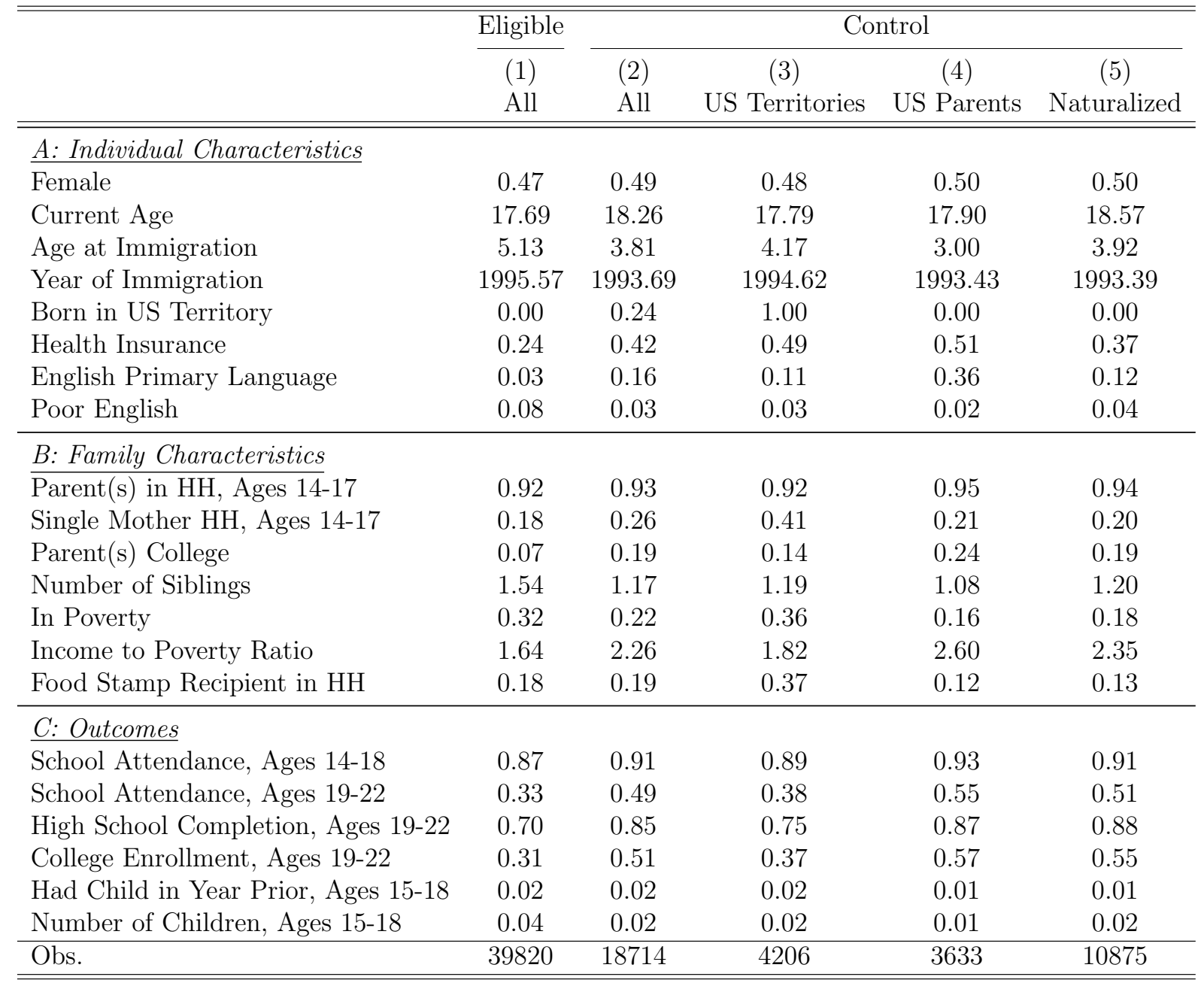

Notes: This table shows summary characteristics for eligible individuals (Column 1), and the comparison group (Columns 2-5; entire (Column 2), born in US territories (Column 3), born to American parents abroad (Column 4), naturalized (Column 5)). Eligible individuals are defined as non-citizen immigrants, and the comparison group is comprised of citizen immigrants. Data: 2005-2011 American Community Survey. Sample is composed of Hispanic foreign born individuals ages 14 to 22 who immigrated by age 10 and by 2007 . 
Table A.2: Effect of DACA on Main Outcomes, Hispanics - Accounting for Time Trends

\begin{tabular}{|c|c|c|c|}
\hline & No Trend & Linear Trend & De-Trend \\
\hline \multicolumn{4}{|c|}{ A: School Attendance, Ages 14-18 } \\
\hline \multirow[t]{2}{*}{ Eligible*Post } & $0.022^{* * *}$ & $0.033^{*}$ & $0.032^{* * *}$ \\
\hline & $(0.008)$ & $(0.017)$ & $(0.008)$ \\
\hline Mean Y & 0.891 & 0.891 & 0.891 \\
\hline Individuals & 54015 & 54015 & 54015 \\
\hline \multicolumn{4}{|c|}{ B: High School Completion, Ages 19-22 } \\
\hline \multirow[t]{2}{*}{ Eligible*Post } & $0.059^{* * *}$ & $0.053^{* * *}$ & $0.057^{* * *}$ \\
\hline & $(0.010)$ & $(0.019)$ & $(0.011)$ \\
\hline Mean Y & 0.781 & 0.781 & 0.781 \\
\hline Individuals & 38704 & 38704 & 38704 \\
\hline \multicolumn{4}{|c|}{ C: College Enrollment, Ages 19-22 } \\
\hline \multirow[t]{2}{*}{ Eligible*Post } & 0.013 & $0.033^{*}$ & $0.037^{* *}$ \\
\hline & $(0.010)$ & $(0.018)$ & $(0.015)$ \\
\hline Mean Y & 0.407 & 0.407 & 0.407 \\
\hline Individuals & 38704 & 38704 & 38704 \\
\hline
\end{tabular}

Notes: This table shows the sensitivity of the difference-in-difference estimates of the impact of DACA on schooling outcomes of eligible youth, when using different methods to account for differential linear trends by eligibility. Column (1) shows our baseline results when we do not control for trends, Column (2) shows the estimates when we include an indicator for eligibility interacted with year, and Column (3) shows the estimates when we perform a two-step procedure, in which we first estimate a regression of each outcome and covariate on an indicator for eligibility interacted with year using the years 2005-2011, and then estimate the difference-in-difference on the residuals. See the notes of Table 1 for the definition of eligibility, high take-up, control variables, clustering, and sample weights. ${ }^{*} \mathrm{p}<0.10,{ }^{*} * \mathrm{p}<0.05,{ }^{*} * * \mathrm{p}<0.01$. Data: 2005-2015 American Community Survey. Sample is composed of Hispanic foreign born individuals ages 14-18 (Panel A) or 19 to 22 (Panels B and C) who immigrated by age 10 and by 2007 . 
Table A.3: Effect of DACA on Main Outcomes, Hispanics Inverse Propensity Score Weighting

\begin{tabular}{|c|c|c|c|}
\hline & All & Hispanic & High Take-Up \\
\hline \multicolumn{4}{|l|}{ A: In School, Age 14-18 } \\
\hline Eligible*Post & $\begin{array}{l}0.012^{* *} \\
(0.005)\end{array}$ & $\begin{array}{l}0.021^{* *} \\
(0.008)\end{array}$ & $\begin{array}{c}0.030^{* * *} \\
(0.008)\end{array}$ \\
\hline Individuals & 109170 & 51727 & 46234 \\
\hline \multicolumn{4}{|l|}{ B: High School Completion, Ages 19-22 } \\
\hline Eligible*Post & $\begin{array}{c}0.036^{* * *} \\
(0.006)\end{array}$ & $\begin{array}{c}0.055^{* * *} \\
(0.010)\end{array}$ & $\begin{array}{c}0.066^{* * *} \\
(0.009)\end{array}$ \\
\hline Individuals & 78199 & 36994 & 33178 \\
\hline \multicolumn{4}{|l|}{ C: College Attendance, Ages 19-22 } \\
\hline Eligible*Post & $\begin{array}{l}0.019^{*} \\
(0.010)\end{array}$ & $\begin{array}{c}0.015 \\
(0.011) \\
\end{array}$ & $\begin{array}{c}0.016 \\
(0.013)\end{array}$ \\
\hline Individuals & 78199 & 36994 & 33178 \\
\hline \multicolumn{4}{|c|}{$\begin{array}{l}\text { Notes: This table shows the difference-in-difference estimates of the impact of DACA on } \\
\text { schooling outcomes of eligible youth, when using inverse propensity score weighting. We } \\
\text { predict the propensity to be eligible using the demographics in Equation } 1 \text {, as well as house- } \\
\text { hold poverty, and dummies for whether the individual primarily speaks English, primarily } \\
\text { speaks Spanish, is fluent in English, and lives in a metropolitan area. For regressions of } \\
\text { schooling attendance between ages } 14 \text { to } 18 \text {, we also include additional controls for family } \\
\text { composition. See the notes of Table } 1 \text { for the definition of eligibility, high take-up, control } \\
\text { variables, clustering, and sample weights. }{ }^{*} p<0.10, * * p<0.05, * * * * 0.01 \text {. Data: } 2005- \\
2015 \text { American Community Survey. Sample is composed of foreign born individuals who } \\
\text { immigrated by age } 10 \text { and by } 2007 \text {. }\end{array}$} \\
\hline
\end{tabular}

Table A.4: Effect of DACA on School Attendance, California County Data

\begin{tabular}{lccc}
\hline \hline & $(1)$ & $(2)$ & $(3)$ \\
& Enrollment & Math Test Takers & ELA Test Takers \\
\hline High-Eligible County*Post & 0.042 & $0.024^{* * *}$ & $0.013^{*}$ \\
& $(0.026)$ & $(0.009)$ & $(0.007)$ \\
\hline Mean Y & .76 & .32 & .32 \\
Counties & 34 & 34 & 34 \\
Obs & 374 & 340 & 340 \\
\hline \hline
\end{tabular}

Notes: This table shows the difference-in-difference estimates of the impact of DACA on various measures of school attendance using county-level variation from California. Treated counties are those with an above-median share of Hispanics that are DACA-eligible. The outcomes are high school enrollment (column 1), the number students taking the Math CAHSEE exam (column 2) and the number of students taking the ELA CAHSEE exam (column 3). All of these attendance measures are expressed as a share of the average Hispanic population aged 14-18 in the county between 2005 and 2011. Post is an indicator for 2012 or after. Regressions include county fixed effects, year fixed effects, and control for the county unemployment rate (See Equation 2). Regressions are weighted by the average number of Hispanics aged 14 to 18 in the county in the 2005-2011 ACS, and standard errors are clustered by county. ${ }^{*} \mathrm{p}<0.10,{ }^{* *} \mathrm{p}<0.05,{ }^{* * *} \mathrm{p}<0.01$. Data: Enrollment data for academic years 2005/06 to 2015/16 and CAHSEE data for 2005/06 to 2014/15, provided by the California Department of Education. 
Table A.5: Effect of DACA on California High School Exit Exam Performance

\begin{tabular}{|c|c|c|c|c|c|c|}
\hline & \multicolumn{3}{|c|}{ Math } & \multicolumn{3}{|c|}{ 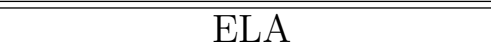 } \\
\hline & Tested & Pass & Score & Tested & Pass & Score \\
\hline \multicolumn{7}{|l|}{ A: Grade 10} \\
\hline High Share DACA Eligible ${ }^{*}$ Post & $\begin{array}{c}0.011^{*} \\
(0.006)\end{array}$ & $\begin{array}{c}-0.023^{* * *} \\
(0.006)\end{array}$ & $\begin{array}{c}-2.963^{* * *} \\
(0.751)\end{array}$ & $\begin{array}{l}0.010^{*} \\
(0.005)\end{array}$ & $\begin{array}{c}-0.011^{* * *} \\
(0.003)\end{array}$ & $\begin{array}{r}-1.597^{* * *} \\
(0.448)\end{array}$ \\
\hline Mean Y & 0.18 & 0.74 & 374.20 & 0.18 & 0.74 & 370.63 \\
\hline Observations & 340 & 340 & 340 & 340 & 340 & 340 \\
\hline \multicolumn{7}{|l|}{ B: Grade 11} \\
\hline High Share DACA Eligible ${ }^{*}$ Post & $\begin{array}{c}0.008^{* * *} \\
(0.002)\end{array}$ & $\begin{array}{l}-0.011 \\
(0.009)\end{array}$ & $\begin{array}{l}-0.586 \\
(0.595)\end{array}$ & $\begin{array}{l}0.004^{* *} \\
(0.002)\end{array}$ & $\begin{array}{c}0.009 \\
(0.008)\end{array}$ & $\begin{array}{c}0.427 \\
(0.733)\end{array}$ \\
\hline Mean Y & 0.07 & 0.33 & 340.77 & 0.07 & 0.34 & 338.03 \\
\hline Observations & 340 & 340 & 340 & 340 & 340 & 340 \\
\hline \multicolumn{7}{|l|}{ C: Grade 12 } \\
\hline High Share DACA Eligible ${ }^{*}$ Post & $\begin{array}{c}0.005^{* * *} \\
(0.002)\end{array}$ & $\begin{array}{c}0.006 \\
(0.006)\end{array}$ & $\begin{array}{c}0.697 \\
(0.504)\end{array}$ & $\begin{array}{l}-0.001 \\
(0.002)\end{array}$ & $\begin{array}{l}0.017^{* *} \\
(0.007)\end{array}$ & $\begin{array}{l}1.647^{* *} \\
(0.623)\end{array}$ \\
\hline Mean Y & 0.06 & 0.27 & 337.29 & 0.06 & 0.24 & 332.41 \\
\hline Observations & 340 & 340 & 340 & 340 & 340 & 340 \\
\hline
\end{tabular}

Notes: This table shows the difference-in-difference estimates of the impact of DACA on California High School Exit Exam (CAHSEE) performance in counties with an above-median share of Hispanics that are DACA-eligible. The outcomes are the share of Hispanics taking the math or ELA exam (Columns 1 and 3), the share of test takers passing the exam (Columns 2 and 4 ), and the average test score in the county (Columns 3 and 6). The denominator for the shares is the average number of Hispanics ages 14 to 18 in the county between 2005-2011. Post is an indicator for 2012 or after. Regressions include county fixed effects, year fixed effects, and control for the county unemployment rate (See Equation 2). Regressions are weighted by the average number of Hispanics aged 14 to 18 in the county in the 2005-2011 ACS, and standard errors are clustered by county. ${ }^{*} \mathrm{p}<0.10,{ }^{* *} \mathrm{p}<0.05,{ }^{* * *} \mathrm{p}<0.01$. Data: Enrollment data for academic years 2005/06 to 2015/16 and CAHSEE data for 2005/06 to 2014/15, provided by the California Department of Education. 
Table A.6: Effect of DACA on Schooling and Work, By Gender and Age

\begin{tabular}{lcccc}
\hline \hline & \multicolumn{2}{c}{ In School } & \multicolumn{2}{c}{ Not In School } \\
& Any & Sec. & Working Only & Idle \\
\hline \hline A: Male 14-18 & & & & \\
\hline Eligible*Post & $0.021^{* *}$ & $0.024^{* *}$ & -0.013 & -0.012 \\
& $(0.010)$ & $(0.011)$ & $(0.010)$ & $(0.018)$ \\
\hline Mean Y & 0.885 & 0.837 & 0.083 & 0.081 \\
Individuals & 28214 & 28214 & 17315 & 17315 \\
\hline B: Male 16-18 & & & & \\
Eligible*Post & 0.025 & $0.032^{* *}$ & -0.013 & -0.012 \\
& $(0.017)$ & $(0.015)$ & $(0.010)$ & $(0.018)$ \\
\hline Mean Y & 0.836 & 0.759 & 0.083 & 0.081 \\
Individuals & 17315 & 17315 & 17315 & 17315 \\
\hline C: Female 14-18 & & & & \\
Eligible*Post & $0.025^{* *}$ & 0.010 & -0.001 & $-0.026^{* *}$ \\
& $(0.012)$ & $(0.012)$ & $(0.011)$ & $(0.011)$ \\
\hline Mean Y & 0.897 & 0.831 & 0.047 & 0.102 \\
Individuals & 25801 & 25801 & 15573 & 15573 \\
\hline D: Female 16-18 & & & & \\
Eligible*Post & $0.028^{*}$ & -0.001 & -0.001 & $-0.026^{* *}$ \\
& $(0.016)$ & $(0.017)$ & $(0.011)$ & $(0.011)$ \\
\hline Mean Y & 0.851 & 0.741 & 0.047 & 0.102 \\
Individuals & 15573 & 15573 & 15573 & 15573 \\
\hline \hline
\end{tabular}

Notes: Table shows difference-in-differences estimates of the effect of DACA on school attendance (Column 1), attending a secondary school (i.e junior or senior high school, Column 2), working only (Column 3), and being idle (Column 4). See the notes of Table 1 for the definition of eligibility, high take-up, control variables, clustering, and sample weights. ${ }^{*} \mathrm{p}<0.10,{ }^{* *} \mathrm{p}<0.05{ }^{* * *} \mathrm{p}<0.01$. Data: 20052015 American Community Survey. Sample is composed of foreign born individuals who immigrated by age 10 and by 2007 . 


\section{B Converting Difference-in-Difference to ITT}

\section{B.1 ACS ITT}

In order to convert our difference-in-difference estimates in the ACS to ITT estimates, we need to understand the frequency with which youth non-citizens are undocumented. We perform this calculation for the overall population and for the Hispanic population, and for context, we also calculate the share of non-citizens with legal status and the share of the undocumented that are Hispanic.

Estimating the share of all non-citizen youth are undocumented is straightforward. Baker and Rytina (2013) estimate that there were 1.4 million undocumented youth between the ages of 18 and 24 in 2012, and Acosta, Larsen and Grieco (2014) estimate there to be 2.55 million non-citizens of the same ages in the 2012 ACS. Thus, we calculate that $55 \%$ of all non-citizens between the ages of 18 and 24 are undocumented in 2012.

Estimating the share of Hispanic non-citizen youth that are undocumented is more complex, since data are not always available at the level of aggregation that we need for these calculations. Therefore we make the following approximations to get close to these statistics:

1. We use the number of non-citizen Hispanics from the fourteen most common countries of origin to approximate the total number of Hispanic non-citizens. Immigrants from these countries account for $95 \%$ of all Hispanics in the US (Flores, 2017; Passel and Cohn, 2014).

2. We use the share of undocumented among non-citizens from Latin America (LA) (Central America, South America, and the Caribbean) to approximate the share of undocumented among Hispanic non-citizens. We estimate that Latin American immigrants account for at least 94\% of all Hispanic immigrants (Flores, 2017; Passel and Cohn, 2014). ${ }^{36}$

Using these estimates, we calculate:

- $72 \%$ of Hispanic non-citizens are undocumented, as: $\frac{8.75 \mathrm{M} \text { undocumented from LA }}{12.2 \mathrm{M} \text { non-citizens from LA }}=0.72$. Source: Hispanic Origin Profiles table of Flores (2017) and Table 2.1 of Passel and Cohn (2014).

$\circ 55 \%$ of non-citizens have legal status, as $1-\frac{11.2 \mathrm{M} \text { undocumented }}{(42.5 \mathrm{M} \text { foreign born-17.8M citizens })}=0.55$. Source: Figure 5.8 of Lopez, Passel and Rohal (2015).

\footnotetext{
${ }^{36}$ We use data from the fourteen most common countries of origin for Hispanic immigrants to calculate this. Among this group, $99 \%$ of Hispanic immigrants are from Latin America.
} 
$\circ 78 \%$ of the undocumented population are Hispanic, as $\frac{8.75 \mathrm{M} \text { undocumented from LA }}{11.2 \mathrm{M} \text { undocumented }}=0.78$. Source: Table 2.1 of Passel and Cohn (2014).

\section{B.2 California ITT}

We perform two adjustments to obtain the ITT for the California analysis. First, we rescale our estimates to take account of the difference in the underlying treatment across above- and below-median undocumented counties. Since these counties have $17.6 \%$ and $10.4 \%$ share non-citizens among Hispanics, respectively, we divide our estimates by the 7.2 p.p difference in this treatment measure.

Second, we need to account for the fact that not all non-citizens are undocumented, as we did above. We obtain estimates of the undocumented working-age population in California counties in year 2008 from Hill and Johnson (2011) and counts of working non-citizens ages 18-65 by county from the 2008 ACS. We estimate that $85 \%$ of non-citizens in California are undocumented, which yields an adjusted difference of 6.1 p.p. Together, this implies that the ITT is $16.3\left(\frac{1}{0.061}\right)$ times as large as the difference-in-difference estimate. This may be an over-estimate, however, if non-citizens are more likely to be undocumented in areas with a larger share of Hispanic non-citizens. If we assume that the probability of being undocumented is instead $100 \%$ and $70 \%$ (averaging to 85\%) across above- and below-median counties, the scaling factor becomes $9.7\left(\frac{1}{0.176-0.7 \times 0.104}\right)$.

Using this rescaling, our 4.2 p.p. difference-in-difference estimate thus implies an ITT for high school enrollment between 41 p.p. and 68 p.p., and between 12.6 and 21.3 p.p. for ELA test-taking, although the $95 \%$ confidence interval does not allow us to reject zero effect for these outcomes and includes the ACS estimate. When we rescale the lower bound of the $95 \%$ confidence interval for math test-taking, we obtain an ITT between 5.8 and 9.8 p.p.. We speculate that the discrepancy between the ITT in the ACS and CA is caused by possible under-reporting of non-citizens in California, which could inflate the scaling factors we estimate, and spillover effects to native-born Hispanics, which we do not measure in the ACS. 


\section{Extended Conceptual Framework and Elasticity Es- timation}

In this section, we formalize the framework described briefly in Section 3 and derive implications of the framework for education decisions. Schooling levels are denoted by $s$ and include high school drop-out $(D)$, high school diploma $(H S)$, and some college $(C)$, respectively. $O$ represents the country of origin, and in the US $n$ indicates undocumented status, and $\ell$ indicates legal status.

\section{C.1 Set-Up}

Consider the decisions of an undocumented youth in his final year of high school: (i) drop out immediately; (ii) stay in school for one additional year to obtain a diploma; or (iii) commit to enrolling in college after high school. He anticipates that after he has completed schooling, he will work either in the US or, if deported, in his country of origin. For simplicity, we assume that he cannot return to the US once deported, such that the deportation risk is equivalent to the deportation risk net of the probability of return.

His expected lifetime earnings are the weighted sum of yearly wages in the US and yearly wages in their country of origin, where the weights are given by the expected years of work in the US versus expected years of work in the country of origin. ${ }^{37}$ If an individual drops out of high school, he works the maximum number of years, equal to the difference between retirement age and his current age, $T$; otherwise, his working years are equal to $T-\alpha$, where $\alpha$ is the number of years spent in additional schooling. When we empirically estimate lifetime earnings, we assume $T=43$, the difference between age 18 and $60, \alpha=1$ if an individual chooses to complete high school, and $\alpha=2$ if an individual chooses to attend some college. ${ }^{38}$

Given a deportation risk, $d$, the expected number of years spent working in the US is the cumulative probability that they are not deported, given by $Y_{\tau}^{U S}=\sum_{t=\alpha}^{T}\left(1-d_{\tau}\right)^{t}$. The number of years spent working in one's country of origin is then $T-\alpha-Y_{\tau}^{U S}$. For simplicity, we assume yearly wages are static and can hence describe expected lifetime earnings for different each status and schooling combination. We abstract from discounting in the notation to have a more parsimonious model, but account for a $5 \%$ discount factor in our empirical

\footnotetext{
${ }^{37}$ It is worth mentioning that we have not explicitly included the nontrivial tuition costs of college in this framework, but to the extent college tuition remains unchanged after DACA, introducing a fixed college tuition cost would lead to the same result.

${ }^{38} \mathrm{We}$ assign the wage associated with some college after one year of college to match our empirical work, where we will measure college attendance as having attended at least one year of college.
} 
estimates. $^{39}$ The expected lifetime earnings before $(\tau=0)$ and after $(\tau=1)$ DACA are:

$$
\begin{aligned}
& \omega_{0}^{s}=w^{O, s} \cdot Y_{0}^{O}+w^{n, s} \cdot Y_{0}^{U S} \\
& \omega_{1}^{s}=w^{O, s} \cdot Y_{1}^{O}+w^{\ell, s} \cdot Y_{1}^{U S}
\end{aligned}
$$

We assume that the policy affected the anticipated years of work in the US and in the origin country by lowering the deportation risk $\left(Y_{1}^{U S}>Y_{0}^{U S}\right)$, and also allowing individuals to earn higher wages associated with legal status in the US $\left(w^{\ell, s}>w^{n, s}\right)$. We ignore any general equilibrium changes in market wages for any education level in either the US or abroad. Additionally, we assume high school dropouts do not see any change in deportation risk and cannot access legal wages since choosing to they are ineligible for DACA. Hence, the expected lifetime wages of a high school dropout are equivalent before and after DACA,

$$
\omega_{1}^{D}=\omega_{0}^{D}=w^{O, D} \cdot Y_{0}^{O}+w^{n, D} \cdot Y_{0}^{U S}
$$

The youth arrives at his decision by comparing expected lifetime earnings under each schooling decision and status, and choosing the option that yields the highest net benefit. Specifically, he decides to finish high school if $\omega_{\tau}^{H S}-\omega_{\tau}^{D}>0$. He then enrolls in college if $\omega_{\tau}^{C}-\omega_{\tau}^{H S}>0$.

This setup allows us to conveniently analyze the expected impacts of DACA. First, DACA should increase the number of high school graduates if it increases the return to high school. In this simple framework, the return to high school is simply the difference between the dropout wage and the high school wage $\left(\omega_{\tau}^{H S}-\omega_{\tau}^{D}\right)$. The change in the return to high

\footnotetext{
${ }^{39}$ For example, to incorporate a discount rate $r$ for wages prior to DACA we set $\omega_{0}^{s}=\sum_{t=\alpha}^{T} \frac{w^{O, s}}{(1+r)^{t}} \cdot[1-$ $\left.\left(1-d_{\tau}\right)^{t}\right]+\frac{w^{n, s}}{(1+r)^{t}} \cdot\left(1-d_{\tau}\right)^{t}$.
} 
school after DACA is,

$$
\begin{aligned}
& \left(\omega_{1}^{H S}-\omega_{1}^{D}\right)-\left(\omega_{0}^{H S}-\omega_{0}^{D}\right) \\
& =\left(\omega_{1}^{H S}-\omega_{0}^{D}\right)-\left(\omega_{0}^{H S}-\omega_{0}^{D}\right), \text { following from equation } C .1 \\
& =\omega_{1}^{H S}-\omega_{0}^{H S} \\
& =\left(w^{O, H S} \cdot Y_{1}^{O}+w^{\ell, H S} \cdot Y_{1}^{U S}\right)-\left(w^{O, H S} \cdot Y_{0}^{O}+w^{n, H S} \cdot Y_{0}^{U S}\right)
\end{aligned}
$$

To further simplify the expression we add and subtract $Y_{1}^{U S} \cdot w^{n, H S}$,

$$
\begin{aligned}
& =w^{O, H S} \cdot\left(Y_{1}^{O}-Y_{0}^{O}\right)+w^{n, H S} \cdot\left(Y_{1}^{U S}-Y_{0}^{U S}\right)+\left(w^{\ell, H S}-w^{n, H S}\right) \cdot Y_{1}^{U S} \\
& =\underbrace{\left(w^{n, H S}-w^{O, H S}\right) \cdot\left(Y_{0}^{O}-Y_{1}^{O}\right)}_{\text {US premium, if non-legal } \times \Delta \text { deportation risk }}+\underbrace{\left(w^{\ell, H S}-w^{n, H S}\right) \cdot Y_{1}^{U S}}_{\text {legal premium }}
\end{aligned}
$$

The resulting expression elucidates two potential ways in which DACA may incentivize individuals to attain a high school diploma:

1. By changing the deportation risk, DACA affects the number of anticipated work years spent in the country of birth, and hence the number of expected years that undocumented individuals can earn US wages rather than home country wages. DACA will thus incentivize high school graduation if $\left(Y_{0}^{O}-Y_{1}^{O}\right)>0$ and $\left(w^{n, H S}-w^{O, H S}\right)>0-$ i.e. that individuals actually perceived a decline in deportation risk and decrease in expected work years abroad, and that the wages paid to undocumented high school graduates in the US are greater than the wages they could earn as high school graduates abroad (i.e. there is a "US premium").

2. By providing work authorization, DACA allows individuals to earn the high school wages paid to those with legal status. This is a benefit that encourages high school graduation if $\left(w^{\ell, H S}-w^{n, H S}\right)>0$ (i.e. there is a "legal premium").

Using the same framework, we can assess how DACA affects the decision to enroll in college. Specifically, we compare the returns to college - defined here as the difference between expected lifetime earnings associated with some college and a high school diploma 
- before and after DACA:

$$
\begin{aligned}
\left(\omega_{1}^{C}-\omega_{1}^{H S}\right)-\left(\omega_{0}^{C}-\omega_{0}^{H S}\right) & =\left(w^{O, C} \cdot Y_{1}^{O}+w^{\ell, C} \cdot Y_{1}^{U S}\right)-\left(w^{O, H S} \cdot Y_{1}^{O}+w^{\ell, H S} \cdot Y_{1}^{U S}\right) \\
& -\left(w^{O, C} \cdot Y_{0}^{O}+w^{n, C} \cdot Y_{0}^{U S}\right)+\left(w^{O, H S} \cdot Y_{0}^{O}+w^{n, H S} \cdot Y_{0}^{U S}\right) \\
& =\left(w^{O, C}-w^{O, H S}\right) \cdot Y_{1}^{O}+\left(w^{n, C}-w^{n, H S}\right) \cdot Y_{1}^{U S} \\
& -\left[\left(w^{O, C}-w^{O, H S}\right) \cdot Y_{0}^{O}+\left(w^{n, C}-w^{n, H S}\right) \cdot Y_{0}^{U S}\right]
\end{aligned}
$$

Similar to before, we can further simplify the expression by adding and subtracting $\left(w^{n, C}-\right.$ $\left.w^{n, H S}\right) \cdot Y_{1}^{U S}$,

$$
\begin{aligned}
& =\left(w^{O, C}-w^{O, H S}\right) \cdot\left(Y_{1}^{O}-Y_{0}^{O}\right)+\left(w^{n, C}-w^{n, H S}\right) \cdot\left(Y_{1}^{U S}-Y_{0}^{U S}\right) \\
& +\left[\left(w^{\ell, C}-w^{\ell, H S}\right)-\left(w^{n, C}-w^{n, H S}\right)\right] \cdot Y_{1}^{U S} \\
& =\underbrace{\left[\left(w^{n, C}-w^{n, H S}\right)-\left(w^{O, C}-w^{O, H S}\right)\right] \cdot\left(Y_{0}^{O}-Y_{1}^{O}\right)}_{\text {add'l college return in US vs. O, if non-legal } \times \Delta \text { deportation risk }} \\
& +\underbrace{\left[\left(w^{\ell, C}-w^{\ell, H S}\right)-\left(w^{n, C}-w^{n, H S}\right)\right] \cdot Y_{1}^{U S}}_{\text {add'l college returns for legals in US }}
\end{aligned}
$$

Hence, simplification gives us a similar expression as before, where the last line follows from the fact that $Y_{1}^{U S}-Y_{0}^{U S}=Y_{0}^{O}-Y_{1}^{O}$.

We expect DACA to incentivize college enrollment in two distinct ways:

1. Similarly to above, DACA affects the number of expected years that undocumented individuals can earn the US college wage premium. This will incentivize high school graduation if $Y_{0}^{O}-Y_{1}^{O}>0$ and $\left(w^{n, C}-w^{n, H S}\right)-\left(w^{O, C}-w^{O, H S}\right)>0$ - i.e. that individuals actually perceived a decline in deportation risk and decrease in expected work years abroad, and that the college wage premium paid to undocumented in the US is greater than the college wage premium they could earn abroad.

2. By providing work authorization, DACA allows individuals to earn the college wage premium associated with legal status $\left(w^{\ell, C}-w^{\ell, H S}\right)$, rather than the college wage premium associated with undocumented status $\left(w^{n, C}-w^{n, H S}\right)$. This is a benefit that encourages college enrollment if $\left(w^{\ell, C}-w^{\ell, H S}\right)-\left(w^{n, C}-w^{n, H S}\right)>0$.

To solidify this intuition, we illustrate the earnings-schooling profile before and after DACA in Figure C.1. This figure illustrates the discrete increase in the return to high school after DACA and assumes that the returns to college also increase. 
Figure C.1: Returns to Education, Before and After DACA

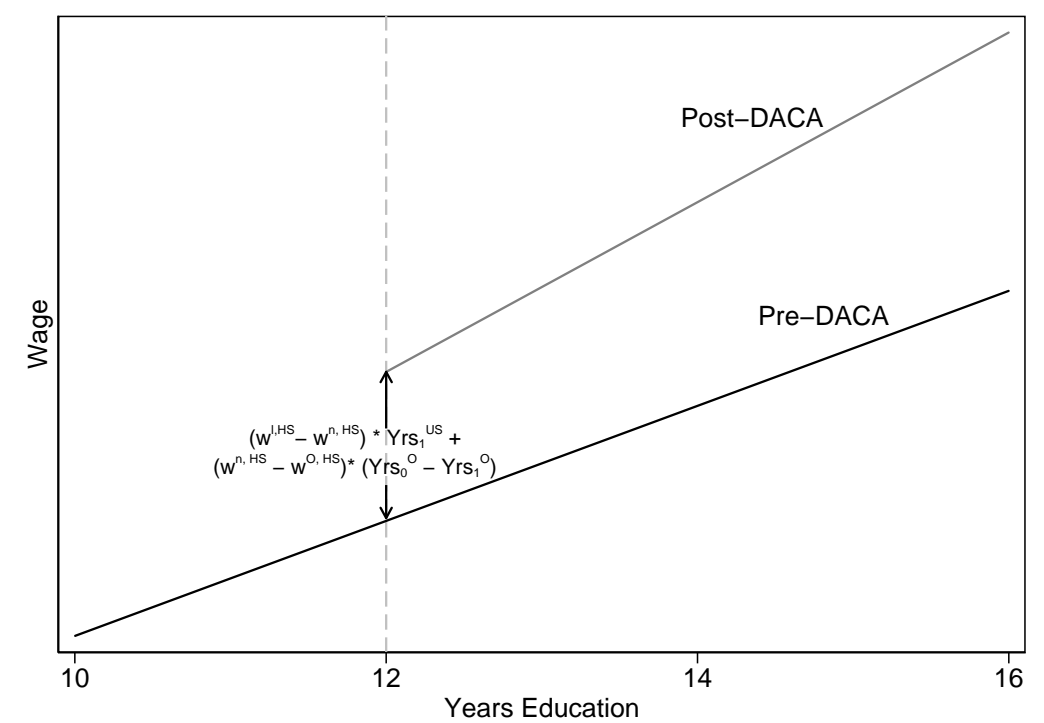

Notes: This figure shows the hypothetical changes in returns to education due to DACA. The vertical axis measures wages, while the horizontal axis measures years of education.

\section{C.2 Estimating the Elasticity of Schooling}

In our estimation of the elasticity, we estimate life time earnings using this model with a few adjustments. First, we allow $d$ to vary by age (18 to 24,25 to 34,35 to 44,45 to 54 , and 55 to 60$)$ and sex based on the tabulations of deportations. Second, we calculate $w^{n, s}, w^{\ell, s}$ and $w^{s, O}$ as the expected annual earnings by multiplying annual earnings for each country, schooling, and legal status by the probability of working for that group. Table C.1 shows the inputs into the expected wages before and after DACA by sex. We pair these inputs with the implied ITT estimates of DACA for Hispanics that we calculate in Section 8 divided by the mean rate of schooling of Hispanics in our sample to obtain the percent increase in schooling. The resulting elasticity of schooling estimates are in Table 5. 
Table C.1: Wages and Returns from DACA - Inputs into Elasticity Calculation

\begin{tabular}{lccc}
\hline \hline & All & Female & Male \\
\hline \hline A: Inputs for Calculation of Returns & & & \\
Dropout Wages - Mexico & 1733 & 821 & 2751 \\
HS Wages - Mexico & 2631 & 1566 & 3677 \\
Some College Wages - Mexico & 5143 & 3616 & 6844 \\
Dropout Wages - U.S. Noncitizens & 4469 & 2280 & 6005 \\
HS Wages - U.S. Noncitizens & 5471 & 3667 & 6864 \\
Some College Wages - U.S. Noncitizens & 7143 & 5778 & 8536 \\
Dropout Wages - U.S. Citizens & 5270 & 3518 & 6874 \\
HS Wages - U.S. Citizens & 8355 & 6480 & 10180 \\
Some College Wages - U.S. Citizens & 15397 & 12057 & 19552 \\
Deportation Risk, Ages 16-18 - Prior to DACA & 0.035 & 0.008 & 0.058 \\
\hline B: Expected Years & & & \\
Years illegal in U.S. - Prior to DACA & 16.467 & 33.472 & 11.168 \\
Years in Mexico - Prior to DACA & 26.533 & 9.528 & 31.832 \\
Years legal in U.S. - Prior to DACA & 0.000 & 0.000 & 0.000 \\
Years in Mexico - 4 Year DACA & 21.187 & 7.580 & 26.580 \\
Years illegal in U.S. - 4 Year DACA & 17.862 & 31.470 & 12.470 \\
Years legal in U.S. - 4 Year DACA & 3.950 & 3.950 & 3.950 \\
Years in Mexico - 6 Year DACA & 17.996 & 6.565 & 23.246 \\
Years illegal in U.S. - 6 Year DACA & 19.108 & 30.539 & 13.858 \\
Years legal in U.S. - 6 Year DACA & 5.896 & 5.896 & 5.896 \\
Years in Mexico - Permanent DACA & 4.415 & 4.415 & 4.415 \\
Years illegal in U.S. - Permanent DACA & 0.000 & 0.000 & 0.000 \\
Years legal in U.S. - Permanent DACA & 38.585 & 38.585 & 38.585 \\
\hline C: Returns to Schooling & 28554 & 46345 & 23541 \\
Return to HS - Prior to DACA & 71193 & 72750 & 89736 \\
Return to College - Prior to DACA & 55349 & 33846 & 66405 \\
Change in Return to HS - 6 Year DACA & 26490 & 20555 & 35572 \\
Change in Return to College - 6 Year DACA & 162064 & 115248 & 200205 \\
Change in Return to HS - Permanent DACA & 167412 & 116709 & 229327 \\
Change in Return to College - Permanent DACA & & & \\
\hline \hline
\end{tabular}

Notes: This table shows the inputs to the calculation of the benefits of DACA for all, male, and female DACA-eligible youth under various assumptions of the duration of DACA; 4 years, 6 years, and permanent. Wages in Panel A are expected annual earnings are calculated for each country and education as the probability of being employed times the average annual earnings. Wage and employment data for Mexico are from the 2010 Census. Wages for the US are calculated for adults between the ages of 18 and 60 year old individuals who arrived in the US by age 10 and year 2007 using the 2009 to 2011 ACS. Expected years in Mexico and the US in Panel B are calculated using the equations for $Y^{U S}$ and $Y^{O}$ in Section C. In Panel C, the return to HS is the difference between the expected lifetime earnings for a high school graduate and a high school dropout, and the return to college is the difference between the expected lifetime earnings for an individual with some college and a high school graduate. 
Table C.2: Implied Elasticity of College Enrollment to Wages

\begin{tabular}{lccc}
\hline \hline & \multicolumn{3}{c}{ Expected Duration of DACA: } \\
\cline { 2 - 4 } & 4 Years & 6 Years & Permanent \\
\hline Elasticity - All & 0.282 & 0.104 & 0.017 \\
Elasticity - Males & 0.384 & 0.145 & 0.022 \\
Elasticity - Females & 0.254 & 0.097 & 0.017 \\
\hline \hline
\end{tabular}

Notes: Estimates of the elasticity of college enrollment for all, males, and female DACA-eligible youth, under various expectations of the duration of DACA (4 years, 6 years, and permanent). Elasticity calculated using (1) the implied ITT effects of DACA for Hispanics (see Section 8) and (2) estimates of the wage benefits of DACA using inputs from Table C.1 together with the framework for expected wages in Section C.

Table C.3: Implied Semi-Elasticity of High School Enrollment to Wages

\begin{tabular}{|c|c|c|c|}
\hline & \multirow{2}{*}{$\frac{\text { Actual Dep. Risk, }}{\text { Age-Based }}$} & \multicolumn{2}{|c|}{ Perceived Dep. Risk: } \\
\hline & & $0 \%$ & $30 \%$ \\
\hline \multicolumn{4}{|l|}{ A: 4 Years Exp. Duration } \\
\hline Semi-Elasticity - All & 0.395 & 1.101 & 0.244 \\
\hline Semi-Elasticity - Males & 0.581 & 1.739 & 0.444 \\
\hline Semi-Elasticity - Females & 0.242 & 0.328 & 0.079 \\
\hline \multicolumn{4}{|l|}{ B: 6 Years Exp. Duration } \\
\hline Semi-Elasticity - All & 0.250 & 0.692 & 0.160 \\
\hline Semi-Elasticity - Males & 0.364 & 1.094 & 0.292 \\
\hline Semi-Elasticity - Females & 0.154 & 0.207 & 0.052 \\
\hline \multicolumn{4}{|c|}{ C: Permanent Exp. Duration } \\
\hline Semi-Elasticity - All & 0.085 & 0.172 & 0.045 \\
\hline Semi-Elasticity - Males & 0.121 & 0.272 & 0.081 \\
\hline Semi-Elasticity - Females & 0.045 & 0.051 & 0.014 \\
\hline
\end{tabular}

Notes: Estimates of the semi-elasticity of college enrollment for all, males, and female DACA-eligible youth, under various expectations of the duration of DACA (4 years, 6 years, and permanent). Semi-elasticity calculated using (1) the implied ITT effects of DACA for Hispanics (see Section 8) and (2) estimates of the wage benefits of DACA using inputs from Table C.1 together with the framework for expected wages in Section C. 


\section{High School Graduation by Month in the NLSY97}

The NLSY97 is a longitudinal survey of a nationally representative sample of roughly 9,000 youth that were between the ages of 12 and 16 by December 31, 1996. Respondents are surveyed on an annual basis on a range of topics, including educational progress. We use the NLSY97 to estimate the proportion of youth that receive a high school diploma in each month for individuals that graduate in 4, 5, or 6 years. We calculate the years of high school attended at the time of diploma as the ceiling of the difference between the year and month of diploma and the year and month that high school began. For simplicity, we assume the school year begins in September. Hence, graduating in September at the beginning of one's $4^{\text {th }}$ year is considered as graduating in four years. The statistics below are unweighted, and are unchanged when weighted.

Table D.1: Graduation by Month and Year

\begin{tabular}{lccc}
\hline \hline \multicolumn{3}{c}{ Graduated in: } & \\
& 4 yrs & 5 yrs. & $6+$ yrs. \\
\hline Jan. to Jun. & 0.975 & 0.757 & 0.824 \\
Jul. to Aug. & 0.019 & 0.025 & 0.049 \\
Sep. to Dec. & 0.006 & 0.218 & 0.127 \\
\hline Observations & 6091 & 325 & 102 \\
\hline \hline
\end{tabular}

Notes: Data include individuals surveyed in the NLSY97. Statistics in each column represent the share of individuals that graduate in each set of months among those that graduate in a given number of years. 


\section{E Deportation Risk Analysis}

To measure the risk of deportation in each state, we obtained publicly available Immigration and Customs Enforcement data on aggregate deportations maintained by the Transactional Records Access Clearinghouse. ${ }^{40}$ We obtain the annual deportation rate as the number of interior deportations by state of departure in each fiscal year from 2005-2011 divided by the noncitizen population aged 10-30 in each state, calculated from the ACS. We then take the average of the deportation rate over the 2005-2011 period to create a single pre-DACA measure of deportation risk that we assign to each individual in the ACS based on their current state of residence. Since $55 \%$ of all deportations are in the 10-30 age range, we scale our deportation risk measures by 0.55 .

Figure E.1 ranks states according to this measure of deportation risk. A select few states have very large deportation rates; Louisiana (30\%) being the highest, followed by Washington DC, North Dakota, Arizona and Texas (5.6\% to 9.5\%). The remaining states have deportation rates deportation rates that fall between $0 \%$ and $5 \%$. Because the variation in deportation risk is concentrated in a handful of states, we use a flexible estimation strategy in which we impose no parametric relationship between deportation risk and the impact of DACA, instead visually inspecting for such a relationship.

Our difference-in-difference estimator extends our baseline regression model to allow the coefficient on PostxEligible to vary for each. We also include the two-way interactions of state and eligibility indicators. We then plot state-specific treatment effects in order of the state deportation risk, along with 95\% confidence intervals in Figure E.2. Marker size is proportional to the size of the state's non-citizen population.

\footnotetext{
${ }^{40}$ Data retrieved from http://trac.syr .edu/phptools/immigration/removehistory/.
} 
Figure E.1: Deportation Rate by State Prior to DACA

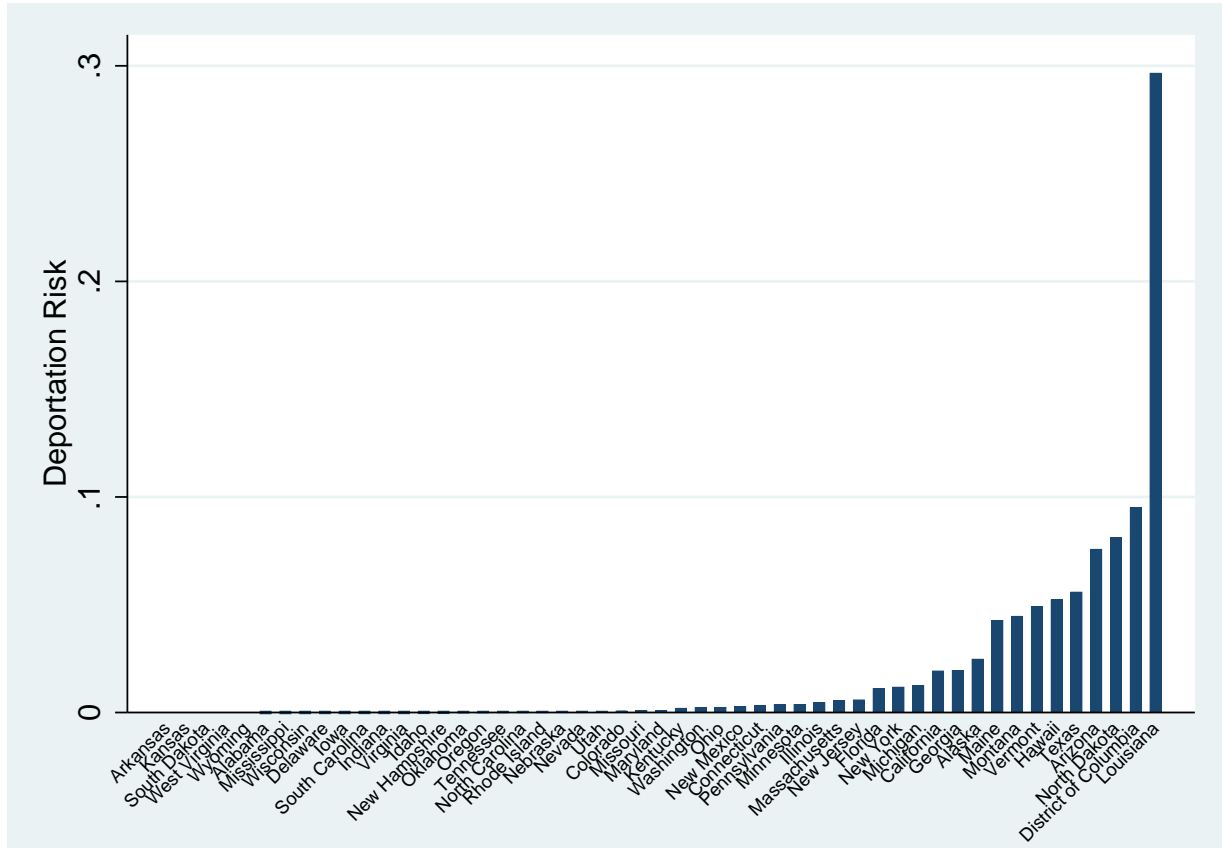

Notes: This figure shows the deportation rate within each state prior to DACA. We define the deportation rate as the number of interior deportations by state of departure in each fiscal year from 2005-2011, obtained from the Transactional Records Access Clearinghouse, divided by the Hispanic non-citizen population aged 10-30 in each state, calculated from the ACS. We adjust these by scaling factor of 0.55 , as $55 \%$ of deportations are of individuals aged 10-30. 


\section{Figure E.2: Effect of DACA on Main Outcomes, Hispanics - Heterogeneity By Deportation Risk}

(a) School Attendance, Ages 14-18

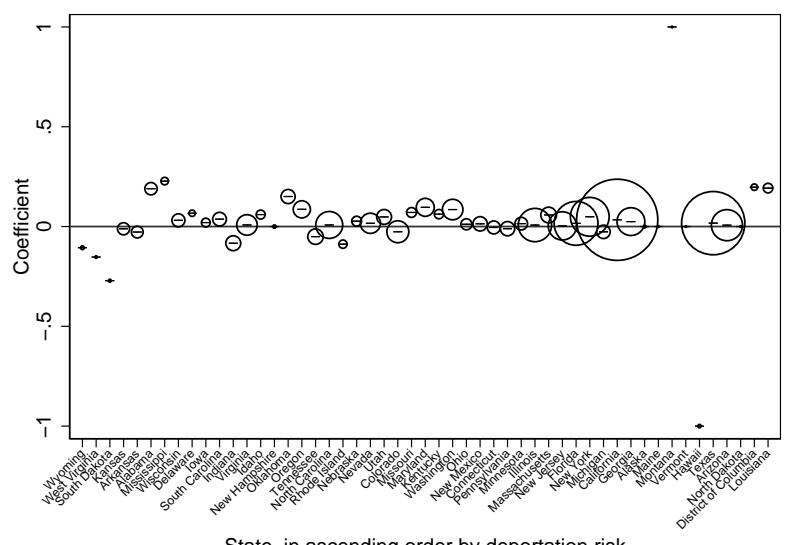

(b) High School Completion, Ages 19-22

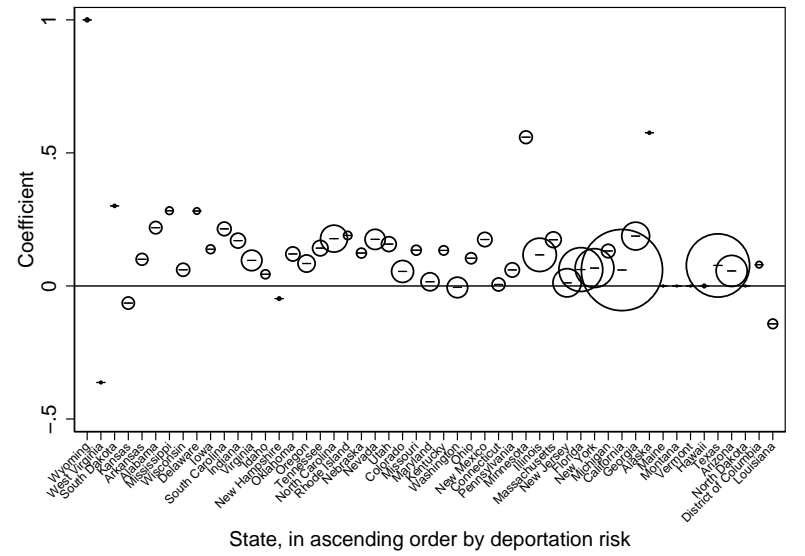

(c) College Enrollment, Ages 19-22

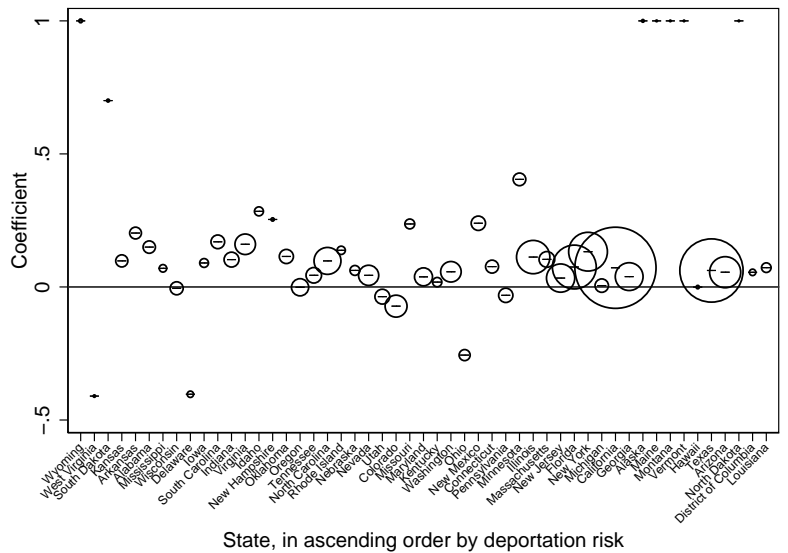

Notes: This figure shows difference-in-differences estimates of the impact of DACA on school attendance, separately by state, with state's ordered according to their deportation risk. Each point represents coefficients from difference-in-difference regressions that estimate the coefficient on the interaction between eligibility, post, and state of residence. States are placed in ascending ordered according to their baseline deportation risk, which is calculated as the number of interior deportations by state of departure in each fiscal year from 2005-2011, obtained from the Transactional Records Access Clearinghouse, divided by the Hispanic non-citizen population aged 10-30 in each state, calculated from the ACS. We adjust these by scaling factor of 0.55 , as $55 \%$ of deportations are of individuals aged 10-30. All regressions control for the following fixed effects: sex, year of immigration, birth region, age of immigration-by-eligibility, age-by-eligibility, state-by-year, race-by-year, and age-by-year (see Equation 1). Standard errors, shown in parentheses, are clustered by state, and regressions are weighted by the survey sampling weights. ${ }^{*} \mathrm{p}<0.10,{ }^{* *} \mathrm{p}<0.05,{ }^{* * *} \mathrm{p}<0.01$. Data: 2005-2015 American Community Survey sample composed of foreign born individuals who immigrated by age 10 and by 2007 . 


\section{F Reconciliation of Post-Secondary Results}

In this section, we review the prior work on the impact of DACA on education. Our goals are to (i) place our estimates in context of the broader literature; (ii) highlight differences in methodologies across these works, and (iii) and propose ways to reconcile our findings. As discussed in the introduction, these earlier studies focus on educational choices posthigh school, and do not analyze high school completion or the school attendance of highschool-aged youth. Therefore, the most comparable estimates in our study are the positive coefficients we find on school attendance for ages 19 to 22 in Panel B of Table 1 and on college attendance for individuals 19 to 30 in Panels B and C of Table 2.

Hsin and Ortega (2017). Hsin and Ortega (2017) study college dropping out in 4-year and 2-year colleges using administrative data from an urban college system. They use a difference-in-difference strategy comparing self-identified undocumented students to all documented students. They find that DACA leads to a 3.7 (s.e.: 0.7 p.p) increase in dropping out of any college. There are seven main differences from our work: Hsin and Ortega (2017) use a sample where (i) the minority of the undocumented are Hispanic as defined by country of birth, ${ }^{41}$ (ii) the comparison group is primarily (75\%) US-born individuals, (iii) individuals are from one metropolitan area; (iv) are unable to distinguish between students that transfer to another system and those that dropout; (v) can track individuals over time; (vi) do not measure effects of DACA on entry into college; (vii) do not have information on age or year of arrival.

Amuedo-Dorantes and Antman (2017). Amuedo-Dorantes and Antman (2017) study school attendance of non-citizen high school graduates ages 18 to 24 using data from the 2000 to 2014 monthly CPS surveys. They use a difference-in-difference approach comparing eligible to non-eligible individuals, before and after October 2012. They find that DACA led to a 11.7 p.p. (s.e.: 3 p.p.) decline in school attendance. There are four main differences from our work: Amuedo-Dorantes and Antman (2017) use a sample that is (i) limited to individuals with a high school degree and (ii) non-citizens, and (iii) is not limited to individuals who immigrated by age 10 or by 2007; and (iv) use the CPS.

Pope (2016). Pope (2016) studies school attendance in multiple samples in the 20052014 ACS surveys, with each sample choice showing the sensitivity of the results to different treatment and comparison groups. The difference-in-difference strategy is the same as Amuedo-Dorantes and Antman (2017). In his preferred sample, focusing on non-citizen high school graduates ages 18 to 30 who entered the US between ages 12 and 19, Pope (2016) finds that DACA led to a 2.1 p.p. (s.e.: 0.09 p.p.) decline in school attendance. There are

\footnotetext{
${ }^{41} 48 \%$ of 2 -year and $35 \%$ of 4 -year undocumented in the sample are from Latin America.
} 
five main differences from our work: Pope (2016) uses a sample that (i) limits to non-citizens that arrived between 12 and 19 and (ii) have a high school degree and (iii) is not limited to individuals who immigrated by age 10 or by 2007; and defines eligible as (iv) having been in the US for 5 years (not since 2007), and (v) currently under 31 (not under 31 as of 2012). ${ }^{42}$

In Table E.1 below we examine the impact of each of the latter four specification choices, as well a few more minor discrepancies in our specifications, on our estimates for the Hispanic sample ages 19 to $22 .{ }^{43}$ The first column shows our main estimate of the effect of DACA on school attendance for ages 19 to 22, a 2.0 p.p. (s.e.: 1.4 p.p.) increase. The next five columns of the table show the estimates when we alter our estimation to converge more closely with Pope, relaxing the age/year of arrival sample criteria (Columns 2-3), the span of our data (Column 4), the length of the post period (Column 5), and removing some control variables (Column 6). The estimate is attenuated when we alter our age of arrival criteria, and remains close to zero and statistically insignificant in the remainder of the columns. Thus, altering our sample choices would reduce the point estimate, but not reverse our conclusion.

In the final four columns of the table, we continue to converge with the Pope estimation strategy, by using his maximum age and year of arrival criteria (Columns 7-8), adding controls for education (Column 9), and restricting to the high school sample (Column 10). The coefficients are now always negative, and statistically significant in two out of the four columns. Qualitatively, changing the eligibility criteria to require only 5 years in the US and restricting to high school graduates make the largest difference. This exercise indicates that the negative or zero effects in Pope (2016) could be in part due to a less stringent application of the policy criteria to determine eligibility as well as selection on high school graduates.

\footnotetext{
${ }^{42}$ While the text of Pope (2016) lists the correct policy requirements for DACA eligibility, the code implements the less stringent eligibility requirements listed here.

${ }^{43}$ We find very similar patterns when we examine a broader set of individuals, ages 18 to 35 , although the effects tend to be more positive across the board.
} 
Table E.1: Sensitivity of School Attendance Estimates to Alternative Assumptions, Hispanics Ages 19-22

\begin{tabular}{|c|c|c|c|c|c|c|c|c|c|c|}
\hline & \multirow{2}{*}{$\frac{\text { Our }}{\text { Estimate }}$} & \multicolumn{5}{|c|}{ Relax our Spec. } & \multicolumn{4}{|c|}{ "Less-Stringent-Policy Defn./Cond'n Educ. } \\
\hline & & No AgeImm & No YearImm & $2005-2014$ & Post $=2013+$ & Pope Controls & Age 31 & 5 yrs US & Ed Controls & HS Only \\
\hline Eligible*Post & $\begin{array}{c}0.020 \\
(0.014)\end{array}$ & $\begin{array}{c}0.002 \\
(0.009)\end{array}$ & $\begin{array}{c}0.002 \\
(0.009)\end{array}$ & $\begin{array}{l}-0.003 \\
(0.009)\end{array}$ & $\begin{array}{l}-0.007 \\
(0.010)\end{array}$ & $\begin{array}{c}-0.007 \\
(0.008)\end{array}$ & $\begin{array}{c}-0.012 \\
(0.008)\end{array}$ & $\begin{array}{c}-0.024^{* *} \\
(0.010)\end{array}$ & $\begin{array}{c}-0.011 \\
(0.009)\end{array}$ & $\begin{array}{l}-0.022^{*} \\
(0.012)\end{array}$ \\
\hline Mean Y & 0.405 & 0.297 & 0.291 & 0.283 & 0.283 & 0.283 & 0.283 & 0.283 & 0.283 & 0.382 \\
\hline Individuals & 38704 & 76235 & 87132 & 80419 & 80419 & 80419 & 80419 & 80419 & 80419 & 51828 \\
\hline
\end{tabular}

Notes: Table shows how our estimated impact of DACA on school attendance for ages 19 to 22 (shown in column 1) changes when we relax our sample restrictions (columns 2 to 6) or when we adopt the sample restrictions or less stringent policy definitions in Pope (2016) (columns 7 to 10). The changes are cumulative, such that column (3) includes the changes from column (2), column (4) includes the changes in columns (2) and (3), etc. In column (2) we include individuals who arrived to the US at all ages; (3) we include individuals who arrived to the US in all years; (4) we drop 2015; (5) we define post to begin in 2013; (6) substitute controls with those in Pope (2016), excluding education controls; (7) change eligibility to require individuals to be under 31 at interview, instead of in 2012 (8) change eligibility to require individuals to have lived in the US for 5 years at interview, instead of in 2012; (9) include controls for attending some college or college (10) restrict to high-school graduates. All regressions control (detailed further in Equation 1) for indicators for sex, year of immigration, birth region (which includes a separate indicator for being born in Mexico), and age of immigration-by-eligibility and age-by-eligibility fixed effects. Also included are state-by-year fixed effect, race-by-year fixed effects, and age-by-year dummies. Standard errors are clustered at the state level. 


\section{G Data Appendix}

This section describes our data, sample selection criteria, and the construction of our variables in greater detail.

\section{G.1 ACS data}

\section{G.1.1 Sample construction}

The data for the individual level analysis on schooling outcomes come from the IPUMS American Community Surveys 2005-2015 (Ruggles et al., 2017). The main analysis sample consists of immigrants to the US who arrived in the US by age 10 and year 2007 and currently reside in the US. We define immigrants as individuals born outside of the 50 states, which includes individuals born in US territories, such as Puerto Rico. We calculate age of arrival as the difference between current age and the number of years since the reported year of arrival. We focus on youth, hence our primary sample is comprised of individuals ages 1422 , but we also examine the high school completion and college attendance of individuals ages 23-30.

\section{G.1.2 ACS treatment, outcomes, and control variables}

- Eligible: We assign a binary indicator for eligibility that is equal to one for individuals in the sample who arrived in the US by age 10 and by year 2007, and who are currently not citizens.

- High Take-up: We assign a binary indicator for being in the high take-up sample that is equal to 1 if birth place is: El Salvador, Mexico, Uruguay, Honduras, Bolivia, Brazil, Peru, Ecuador, Jamaica, Guatemala, Venezuela, Dominican Republic, and Colombia. Each of these countries has a DACA participation rate above $30 \%$ according to the Migration Policy Institute's (MPI) estimates: http://www.migrationpolicy.org/ programs/data-hub/deferred-action-childhood-arrivals-daca-profiles.

- Hispanic: We assign a binary indicator for being hispanic that is equal to one if IPUMS variable hispan is not equal to 0.

- High school completion: We assign a binary indicator for having completed high school that is equal to 1 if an individual has a high school diploma or GED (IPUMS variable educd is equal to 62,63 or 64 ), or if they have completed some college (educd is equal to 65 or above and is not missing) 
- Some college attainment: We assign a binary indicator for having completed some college that is equal to 1 if an individual has attended any college (IPUMS variable educd is equal to 65 or above and is not missing)

- Birth region: We control for indicators for the following 5 birth regions constructed from the IPUMS $b p l$ variable: Mexico $(b p l=200)$, United Kingdom/Europe $(410 \leq b p l$ $\leq 419,700 \leq b p l \leq 701,450 \leq b p l \leq 499)$, Asia $(500 \leq b p l \leq 600)$, Other Latin and South/Central America $(210 \leq b p l \leq 300)$, and Rest of the world.

\section{G.2 California DOE Data}

\section{G.2.1 Data construction}

For our secondary identification strategy, we use data from academic years 2005/06 through 2015/16 provided by the California Department of Education. Data on high school enrollment come from school-grade-level enrollment files covering K-12, available for download at https://www.cde.ca.gov/ds/sd/sd/filesenr.asp. We collapse this data to the county level to match our aggregate measure of undocumented students, totaling the enrollment over all schools in the county. We then add up the enrollment of Hispanics across grades $9,10,11$, and 12 to obtain total high school enrollment for each county.

We also obtain data on county-level CAHSEE performance test performance from the California Department of Education, available for download at https://cahsee.cde.ca. gov/datafiles.asp. We use information on the number of test takers, the share of test takers that pass the exam, and the average test score. These are separately provided by grade, for grades 10,11, and 12, and also in aggregate for grades 10-12.

Once we have constructed these county aggregates, we then keep only the 34 counties that are identified in the ACS, since those are the counties for which we will be able to assign eligibility.

\section{G.2.2 County treatment assignment and control variables}

- Above-median-undocumented: We assign a binary indicator for having a high share of undocumented (our measure of treatment for this analysis) that is equal to 1 if the county has an above-median share of Hispanics that are DACA-eligible. To create this variable, we calculate the share of the Hispanic population aged 14-18 in each county that are DACA-eligible using our ACS sample using the years from 2005 to 2011. We then rank counties by this share, and assign counties to be above median if the share is above the median of the sample. 
- Unemployment rate: We obtain annual unemployment rates for each county from 2005 to 2015 from the Bureau of Labor Statistics (see https://www.bls.gov/lau/). 